\title{
A Validation of Passive Microwave Rain-Rate Retrievals from the Chinese FengYun-3B Satellite
}

\author{
Bin Xu,*,+, PingPing Xie, ${ }^{@}$ Ming Xu,* Lipeng Jiang, ${ }^{\#}$ ChunXiang Shi, ${ }^{\#}$ And RAn You ${ }^{\&}$ \\ * Key Laboratory of Ecosystem Network Observation and Modelling, Institute of Geographic Sciences and Natural \\ Resources, Chinese Academy of Sciences, Beijing, China \\ ${ }^{+}$University of Chinese Academy of Sciences, Beijing, China \\ \# National Meteorological Information Center, China Meteorological Administration, Beijing, China \\ ${ }^{\circledR}$ NOAA/Climate Prediction Center, College Park, Maryland \\ ${ }^{\&}$ National Satellite Meteorological Center, China Meteorological Administration, Beijing, China
}

(Manuscript received 15 July 2014, in final form 31 December 2014)

\begin{abstract}
Level 2 rain-rate retrievals from the Microwave Radiation Imager (MWRI) on board the Chinese FengYun $(F Y)$-3B satellite are verified using minute rainfall measurements from a dense automatic weather station (AWS) network over eastern China for the warm seasons (May-September) of 2012 and 2013. First, analyses of minute rainfall are constructed on a $0.05^{\circ}$ latitude-longitude grid box through interpolation of qualitycontrolled gauge reports. Ground truth for the $F Y-3 B$ rain-rate retrievals is defined as the 5-min mean rate centering at the satellite observation time and over the $0.05^{\circ}$ latitude-longitude grid boxes falling into the target field-of-view (FOV) coverage determined with parallax correction. Parallax displacement is about the same as the height of cloud or half of the $F Y-3 B$ FOV size. Parallax correction is crucial to ensure accurate evaluation and applications of the level 2 precipitation retrievals from $F Y-3 B$ and other satellites, including the Global Precipitation Mission (GPM) core satellite, and should be implemented before the level 2 retrievals may be used as inputs to the level 3 integrated satellite precipitation analyses. $F Y-3 B$ level 2 retrievals present good skills in detecting raining pixels and quantifying rain rate as retrievals from other PMW sensors. However, they tend to miss rainfall from warm and low clouds of small scales and underestimate (overestimate) heavy (light) precipitation. In particular, the limited maximum rain rate yields significant underestimation for many heavy rainfall events. Maximum rainfall detected by the $F Y-3 B$ retrievals for the afternoon orbits is shifted by about $7-8 \mathrm{~km}$ toward the leeward direction, most likely caused by the displacement between the heavy rainfall and tallest cloud top.
\end{abstract}

\section{Introduction}

The last two decades have witnessed tremendous development of new techniques to retrieve precipitation information from satellite observed passive microwave (PMW) radiance (e.g., Grody 1991; Wilheit et al. 1991; Liu and Curry 1992; Petty 1994; Kummerow et al. 2001, 2014; Wang et al. 2009; Gopalan et al. 2010) and to integrate PMW-based precipitation retrievals from multiple sensors with estimates derived from geostationary (GEO) platforms (e.g., Hsu et al. 1997; Turk et al. 2004; Joyce et al. 2004; Huffman et al. 2007, 2014; Ushio et al.

\footnotetext{
Corresponding author address: Bin Xu, National Meteorological Information Center, China Meteorological Administration, 46 South Zhongguancun Street, Haidian District, Beijing 100081, China.

E-mail: xubin@cma.gov.cn
}

2009; Joyce and Xie 2011; Xie and Joyce 2014). Level 2 PMW retrievals of instantaneous precipitation rates at their respective sensor field of view (FOV) and level 3 gridded fields of high-quality, high-resolution global integrated precipitation estimates have been generated routinely and applied widely in weather and climate monitoring, numerical model evaluations, and hydrologic studies (e.g., Dai et al. 2007; Tian et al. 2007; Hong et al. 2007).

Indispensable to the development of these satellite precipitation algorithms are the examination-validation studies aiming to 1) understand the performance of the existing techniques for further refinements (Conner and Petty 1998; Liao et al. 2001; Kummerow et al. 2006; Yang et al. 2006; Lin and Hou 2008; Wolff and Fisher 2008, 2009; Amitai et al. 2009; Munchak and Skofronick-Jackson 2013; Kirstetter et al. 2013, 2014) and 2) quantify errors in the 
products for informed applications (Hossain and Anagnostou 2004; Ebert et al. 2007; Xie et al. 2007; Sapiano and Arkin 2009; AghaKouchak et al. 2011; Tang et al. 2014). Validation studies of the latter category often involve comparisons of gridded estimates (level 3 products) of precipitation accumulated over a time period (e.g., $30 \mathrm{~min}$, hourly, or daily) against a reference field of much higher accuracy (usually gauge-based analyses or gauge-calibrated radar estimates). Examinations of the first category, especially those for the level 2 algorithms/ products, however, require the use of a "ground truth" for instantaneous precipitation rates. It was largely because of this critical requirement that the Tropical Rainfall Measuring Mission (TRMM; Simpson et al. 1988) and the Global Precipitation Measurement (GPM; Hou et al. 2014) projects set up the ground validation effort as one of their integral components (Wolff et al. 2005).

Currently, the majority of validation studies for the PMW level 2 precipitation retrievals published so far used gauge-calibrated radar estimates from the TRMM-GPM ground validation sites or the next-generation quantitative precipitation estimates (Q2; Zhang et al. 2011a) of the National Oceanic and Atmospheric Administration (NOAA). These radar-based estimates exhibit great skills in representing precipitation variations on a fine time-space resolution (down to $5 \mathrm{~min}$ and $1 \mathrm{~km}$ ), especially over oceanic regions close to the radar sites (ideally $<150 \mathrm{~km}$ ). Derived from reflected radiance through an empirical relationship between reflectivity $Z$ and rain-rate $R$, radar estimates themselves are not direct measurements of precipitation. Their quantitative accuracy is compromised by various factors, including partial beam filling, beam overshooting, vertical profile of reflectivity (VPR), inaccurate $Z-R$ relationship, and evaporation beneath the cloud base (Krajewski and Smith 2002; Zhang et al. 2011b). Radar-based precipitation estimates present better quality over regions close to the radar site where the beam height is low enough to capture raining clouds and over ocean where there are few topographic obstacles for radar scanning. Caution is needed in applying radar precipitation estimates to verify satellite retrievals, especially over mountainous regions of shallow convection or for dry climate.

Gauge observations provide direct and relatively accurate measurements of precipitation at the instrument sites. Constructing a gauge-based ground truth of precipitation for the validation of PMW level 2 retrievals, however, requires a station network of sufficient density to ensure accurate estimates of instantaneous precipitation rates over a PMW sensor FOV (typically about $20 \mathrm{~km}$ in diameter). Kirstetter et al. (2013), one of a few published studies utilizing gauge data as the ground truth, verified TRMM Microwave Imager (TMI)-based PMW level 2 retrievals against gauge-based analyses of 5-min rain rates derived from measurements from two dense station networks over West Africa. Despite the advanced interpolation technique applied, uncertainties of substantial magnitude exist in representing 5-min mean precipitation over a TMI FOV of about $12.5 \mathrm{~km}$ in diameter with information captured by a network of approximately $400 \mathrm{~km}^{2}$ per gauge.

In recent years, a network of automatic weather stations (AWSs) has been established by the China Meteorological Administration (CMA) over the eastern half of the country (about $5000000 \mathrm{~km}^{2}$ in area). Measurements of 1-min rain rate made at more than 30000 tipping-bucket gauges from the CMA AWS network provide us with a rare opportunity to examine the performance of PMW level 2 retrievals of instantaneous precipitation at a satellite FOV scale over a wide area of varying weather-climate conditions. In particular, the AWS network is very dense over metropolitan regions in eastern China, with a mean gauge distance of $5 \mathrm{~km}$ or shorter.

Two objectives of this work are 1) to explore an optimal way of utilizing the 1-min rain-rate measurements for the quantification of PMW level 2 retrievals and 2) to examine the performance of the PMW level 2 retrievals of the Chinese FengYun (FY)-3B satellite in delineating raining events and quantifying the precipitation intensity during warm seasons over eastern China. The paper consists of five sections. After the introduction, gauge measurements from the Chinese AWS network and the PMW retrievals from the $F Y-3 B$ satellite will be presented in sections 2 and 3, respectively. They are followed by a description of the examination of the $F Y-3 B$ precipitation retrievals over eastern China in section 4 . A summary will be provided at the end of the paper.

\section{Rainfall measurements and analysis from the Chinese AWS network}

\section{a. Measurements of minute rain rate from the Chinese AWS network}

The CMA's effort to establish a network of AWSs over China started more than a decade ago. As of the end of 2013, the CMA AWS network comprised more than 40000 stations, concentrated mostly over the populated eastern half of the country. During the early years, the AWS measurements were recorded locally and reported to the CMA National Meteorological Information Center (NMIC) with a delay of several weeks. Since 2006, measurements from an increasing number of AWSs are transmitted on a real-time basis to regional meteorological offices and the CMA NMIC for applications 
in weather warnings, decision support, and forecast verification.

The measured meteorological variables and frequency of observation differ depending on the type of the AWSs. Rain rate, however, is measured by tippingbucket gauges at a 1-min interval from virtually all AWSs across the country. Restricted by the use of tipping-bucket gauges, the AWS measurements of rain rate are not performed for stations over the northern and western parts of the country during cold seasons (October-March).

An operational system has been established at the CMA NMIC to perform quality control (QC) for the AWS-observed hourly precipitation from the network (Ren et al. 2010). The QC procedures for hourly precipitation reports are composed of three sets of examinations, including 1) range check, 2) temporal consistency check, and 3) spatial consistency check. The range check identifies and removes suspicious reports beyond the expected range of precipitation variations defined regionally as a function of season using historical data. The temporal consistency check is designed to eliminate bad reports causing unnatural temporal variation patterns of precipitation. Many of the cases eliminated by this QC procedure involve flat time series caused by malfunction or clogging of a tipping-bucket rain gauge. The spatial consistency check, also called a buddy check, identifies outliers through comparison with concurrent hourly precipitation reports from stations within $50 \mathrm{~km}$ of the target AWS.

No operational system has been developed and implemented at CMA NMIC for the QC of the AWS 1-min rainfall reports. In this study, only minute rainfall data for an hourly time period satisfying the following three criteria are selected and used. These criteria are 1) hourly precipitation report for the hour passed the QC procedure described above, 2) no missing minute rainfall reports occurs within the hour, and 3 ) accumulation of the 60-min rainfall reports with the hour matches the amount from the quality-controlled hourly report.

Since the CMA AWS network is very sparse over the western half of the country and the QC procedures are not implemented as thoroughly there, only the AWS 1-min rain-rate measurements over the country east of $95^{\circ} \mathrm{E}$ are utilized in this study. As shown in Fig. 1, most of the eastern provinces in China are well covered by the AWS network. In particular, the network is very dense over many metropolitan regions, where the number of gauges inside a grid box of $0.05^{\circ}$ latitude-longitude $\left(\sim 25 \mathrm{~km}^{2}\right)$ often exceeds two, or approximately $12.5 \mathrm{~km}^{2}$ per gauge. This is much higher than that of the gauge network over West Africa used by Kirstetter et al. (2013) to evaluate TMI retrievals. Availability of 1-min rain-rate measurements

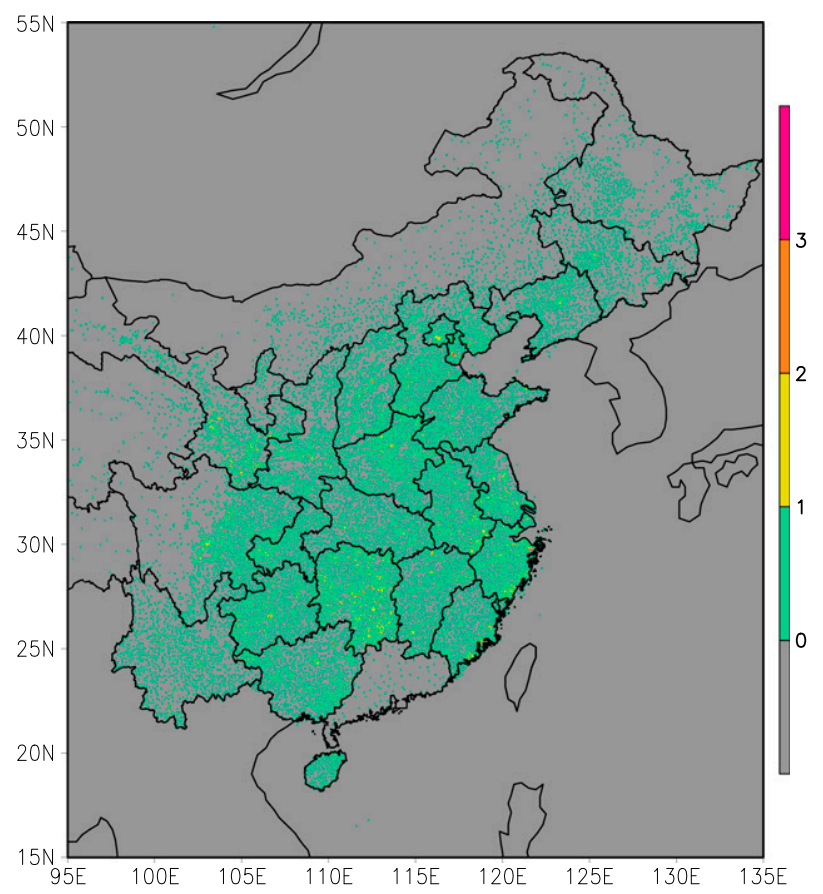

FIG. 1. Number of gauges in a $0.05^{\circ}$ latitude-longitude grid box from the CMA AWS network system.

from the regionally dense network over the majority of eastern China enables the examination of PMW level 2 retrievals of precipitation for an assortment of weather and climate conditions. Since the tipping-bucket measurements of rain rate are not implemented during the cold seasons over the western and northern portions of the target domain, our work reported in this paper only covers the examination for warm season precipitation using data for May-September 2012 and 2013.

\section{b. AWS-based precipitation analysis}

Both the gridbox mean and grid analysis of AWS measurements are tested for use as the ground truth to evaluate the performance of PMW level 2 precipitation retrievals. The gridbox mean is simply defined as the arithmetic mean of measurements from all AWS gauges inside the target grid box. The grid analysis, meanwhile, is computed through interpolation of gauge reports from nearby AWSs using an objective analysis technique. Many techniques are available to interpolate the stationobserved precipitation data. Kirstetter et al. (2013) applied the block-kriging technique to interpolate the station data onto TMI FOV positions. Xie et al. (2007) utilized the optimal interpolation (OI) method of Gandin (1965) to construct gauge-based analysis of daily precipitation over China. Both the kriging and the OI require the quantification of the statistical structure of the target precipitation to tune the model parameters. Creutin and 
Obled (1982), meanwhile, concluded that while a statistical interpolation like the OI performs best with an appropriate definition of parameters, the technique of Shepard (1968), with no need to tune, is capable of generating gauge-based analysis at a quantitative accuracy close to that for the OI. This is confirmed by Chen et al. (2008) in their intercomparison study of gauge analyses created with different interpolation algorithms. In this study, the interpolation technique of Shepard (1968) is applied to define the grid analysis for its good performance and easy implementation.

The algorithm of Shepard (1968) is basically a modified reverse-distance interpolation technique. Precipitation analysis at a grid point is computed as a weighted mean of observed values at nearby gauge stations within a search distance. The search distance is variable depending on the gauge network density, so that 4-10 gauges are included in the calculation. The weighting function is inversely proportional to the gauge-gridpoint distance, creating a sharp gradient in the analyzed precipitation fields. In addition, directional correction is implemented to account for any uneven distribution of gauges in different directions from the target.

Gauge-based analysis of 1-min rain rate is constructed for each minute time step for the warm seasons (MaySeptember) of 2012 and 2013. Although the size of a current-generation PMW sensor FOV ranges from 10 to $30 \mathrm{~km}$, grid analysis of AWS-measured 1-min rain rate is produced on a $0.05^{\circ}$ latitude-longitude grid over all of eastern China. This analysis at the $0.05^{\circ}$ latitude-longitude grid resolution will be aggregated to the respective PMW FOV location and resolution later on and used as the ground truth to validate the satellite retrievals. In addition to the gridbox mean and the grid analysis described above, number of reporting gauges inside each $0.05^{\circ}$ latitudelongitude grid box is also included as a proxy quality index for the gridbox mean and analysis.

Figure 2 illustrates an example of the grid analysis of 1-min rain rate over eastern China at 1520 UTC 21 July 2012. A band of rainfall associated with a rapidly passing frontal system is clearly depicted. The flood-causing heavy rainfall over the capital city Beijing (around $39.9^{\circ} \mathrm{N}, 116.4^{\circ} \mathrm{E}$ ) is well captured, with a maximum 1-min rain rate exceeding $50 \mathrm{~mm} \mathrm{~h}^{-1}$. Precipitation distribution over gauge-sparse regions, such as that over northeastern China, however, is apparently smoothed because of the extended interpolation distance there.

\section{c. Performance of the gauge analysis in representing mean rain rate over an $F O V$}

One important step toward the application of a gaugebased analysis to the verification of satellite retrievals is to identify situations when the quality of the gauge

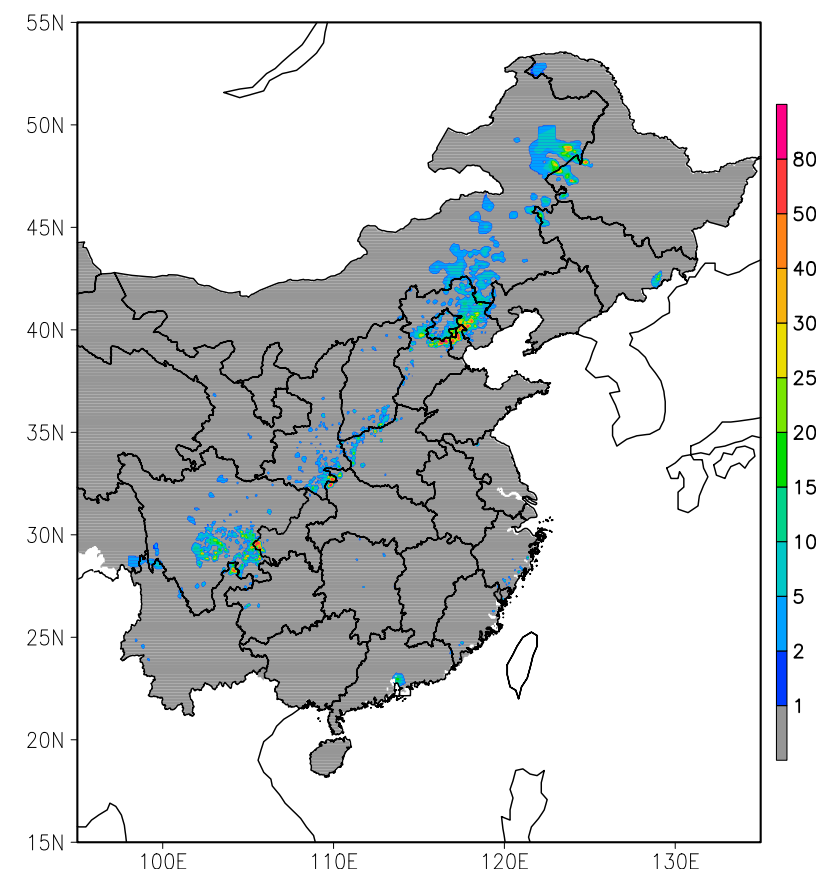

FIG. 2. Analyzed field of 1 -min rain rate $\left(\mathrm{mm} \mathrm{h}^{-1}\right)$ on a $0.05^{\circ}$ latitude-longitude grid over eastern China at 1520 UTC $21 \mathrm{Jul}$ 2012; defined by interpolating station reports from the CMA automatic weather stations through the technique of Shepard (1968).

analysis is adequate to be used as the "truth" for rainfall. Xie and Xiong (2011) performed a synthetic experiment to examine the quantitative accuracy of a gauge-based analysis in representing mean daily precipitation over a $0.25^{\circ}$ latitude-longitude grid box by defining the ground truth as the arithmetic mean of station reports over a region covered by a very dense network and comparing gauge analyses defined from various subsets of station data of reduced network densities against the ground truth. In this study, a similar strategy is adopted to investigate the performance of AWS gauge-based analysis in representing 1-min rain rate averaged over a PMW sensor FOV. Since one objective of this study is to quantify the performance of the $F Y-3 B$ level 2 precipitation retrievals, the target FOV size is set as a circular area of $25 \mathrm{~km}$ in diameter, as will be described in the next section.

Seven metropolitan regions with very dense AWS networks are selected for our experiment. They are, from north to south, Shenyang $\left(41.575^{\circ} \mathrm{N}, 123.325^{\circ} \mathrm{E}\right)$, Beijing $\left(39.925^{\circ} \mathrm{N}, 116.325^{\circ} \mathrm{E}\right)$, Tianjin $\left(39.125^{\circ} \mathrm{N}, 117.225^{\circ} \mathrm{E}\right)$, Shanghai $\left(29.775^{\circ} \mathrm{N}, 121.675^{\circ} \mathrm{E}\right)$, Chengdu $\left(30.675^{\circ} \mathrm{N}\right.$, $\left.104.075^{\circ} \mathrm{E}\right)$, Fuzhou $\left(25.425^{\circ} \mathrm{N}, 119.075^{\circ} \mathrm{E}\right)$, and Guilin $\left(25.275^{\circ} \mathrm{N}, 110.325^{\circ} \mathrm{E}\right)$. A circular area $25 \mathrm{~km}$ in diameter covering each of the seven metropolitan regions is identified to represent an $F Y-3 B$ FOV. The number of AWS gauges inside an FOV coverage ranges from 18 in 
Shenyang to 34 in Shanghai, ensuring the definition of the ground truth with very high quality.

Analyzed fields of 1-min rain rate are first produced on a $0.05^{\circ}$ latitude-longitude grid through the Shepard algorithm using reports from subsets of stations over the target grid box and adjacent regions. A total of 500 groups of subsampled station combinations are simulated through random selection from all available stations to mimic the CMA AWS gauge network density and configurations. The 500 combinations were necessary to ensure stable statistics for the gauge analysis performance. Analyzed values at all $0.05^{\circ}$ latitude-longitude grid boxes inside an FOV are then averaged to define the gauge analysis for the FOV. For comparison purposes, the gridbox mean of 1-min rain rate is also calculated as the arithmetic mean of the subset station reports inside the FOV. To examine the performance of the gauge analysis for various averaging time scales, interpolated and gridbox mean of 1-min rainfall over an FOV are accumulated to 3-, 5-, 10-, 30-, and 60-min time periods and compared against the truth.

Correlation (random error) of the gauge analysis increases (decreases) rapidly with the local gauge network density, reaching to a relatively stable level for gauge analysis with five or more gauges inside an FOV of $\sim 25 \mathrm{~km}$ in diameter (Fig. 3). For example, correlation for the gauge analysis of 5-min rain rate increases from $\sim 0.4$ for an FOV with no reporting gauge to $\sim 0.68$ for an FOV with one gauge and reaches close to 0.9 when five or more gauges are available inside an FOV. Accuracy of the gauge analysis improves with the averaging time scales. For gauge analysis over an FOV with five reporting gauges, correlation is refined from $\sim 0.87$ for the 1-min rain rate to $\sim 0.90$ for the 5 -min rain rate and $\sim 0.94$ for hourly rainfall (Fig. 3, top). Bias of substantial magnitude (Fig. 3, bottom) is observed when no reporting gauge is located inside the target FOV and the analysis is defined through interpolation of observations from adjacent regions. The bias diminishes when reports are available from one or more gauges inside the target FOV. The gauge-based analysis exhibits consistently superior performance than the gridbox mean in representing the mean precipitation over an FOV (Fig. 4). It is clear from the experiment results that the gauge-based analysis is a better choice for the ground truth of precipitation and that only the gauge analysis over an $F Y-3 B$ FOV of five or more reporting stations may be used as the high-quality ground truth for 5-min rain rate. Although a gauge analysis for longer averaging time scale presents better quality, as shown in Fig. 3, a gauge analysis for a 5 -min mean rain rate is selected as the ground truth for the evaluation of $F Y-3 B$ level 2 retrievals after considering the gauge analysis quality and the representativeness of the gauge analysis for "instantaneous" rain rates.

\section{3. $F Y-3 B$ level 2 retrievals and the parallax correction}

\section{a. The Chinese FY-3B satellite and its PMW instrumentation}

Launched on 5 November 2010, the $F Y$-3B is the second vehicle of the CMA next-generation polar orbiting satellites. The $F Y-3 B$ flies on a sun-synchronous orbit at a height of $836 \mathrm{~km}$ and an inclination angle of $98.75^{\circ}$, circling the earth every $101.6 \mathrm{~min}$ with its equatorial crossing time (ECT) for the ascending and descending nodes at 1340 and 0140 local standard time (LST), respectively. The primary instrument for the precipitation retrieval is the Microwave Radiation Imager (MWRI) that measures the radiance of both the vertical and horizontal polarizations on five microwave frequencies, including $10.65,18.7,23.8,36.5$, and $89.0 \mathrm{GHz}$. The $F Y$-3B takes a conical scan mode with an antenna view angle of $45^{\circ}$, forming a satellite elevation angle of approximately $37^{\circ}$ from a target at the earth's surface.

\section{b. FY-3B PMW level 2 rain-rate retrievals}

An operational system is developed at the CMA National Satellite Meteorology Center (NSMC) to produce level 2 precipitation retrievals from the $F Y$-3B MWRI PMW measurements (Yang et al. 2013). The precipitation retrieval is performed in two consecutive steps. First, raining FOVs are identified using the brightness temperatures from a combination of MWRI channels through a technique developed in reference of Ferraro and Grody (1994). The combination of PMW channels and the threshold brightness temperatures used to delineate the raining FOVs are selected separately for four types of underlying surfaces, that is, land, water, coast, and snow/ ice coverage.

Intensity of precipitation rate is then quantified for those FOVs classified as raining in the previous step. This is done through a set of multiregression equations between the rain rate and a combination of brightness temperatures at three channels, that is, 18.7, 23.8, and $89 \mathrm{GHz}(\mathrm{V})$. Here again, the determination of the coefficients are conducted separately for different underlying surfaces. Since the TMI level 2 retrievals present relatively a high-quality estimation of instantaneous rain rates over the global domain from $37.5^{\circ} \mathrm{S}$ to $37.5^{\circ} \mathrm{N}$ (e.g., Tang et al. 2014), the precipitation quantification equations for the $F Y-3 B$ are first developed using the TMI retrievals as the truth. Estimates derived from these TMI-calibrated equations are then compared against gauge-measured hourly rainfall at 120 stations over China for a 2-month period of the warm season to fine-tune the equations for MWRI rain-rate retrievals.

Derived from level 1 data resampled at satellite FOVs for 18.7 and $23.8 \mathrm{GHz}(\mathrm{V})$, the $F Y-3 B$ MWRI precipitation 

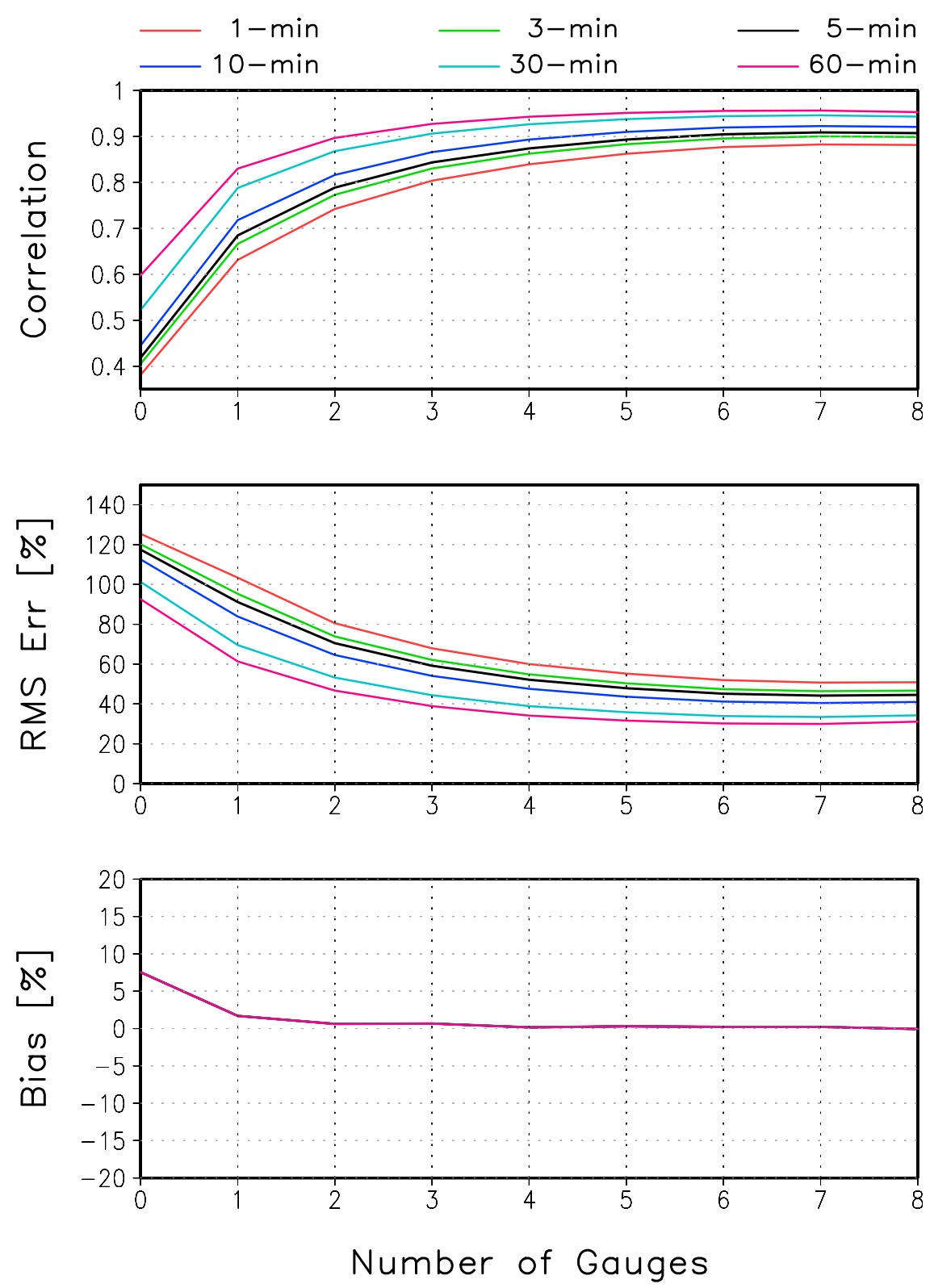

FIG. 3. Accuracy of the gauge-based analysis over a satellite FOV as a function of the number of reporting gauges inside the FOV. Here accuracy is measured by the (top) correlation, (middle) RMS error $\left(\mathrm{mm} \mathrm{h}^{-1}\right)$, and (bottom) relative bias $(\%)$ and computed through comparison against the truth defined as the arithmetic mean of gauge reports from all stations. Results for rain rate of various averaging periods are plotted in different colors, as indicated above.

retrievals are generated for an FOV of $\sim 25 \mathrm{~km}$ in diameter, with a dynamic range of $0-35 \mathrm{~mm} \mathrm{~h}^{-1}$ and retrieval accuracy of $0.1 \mathrm{~mm} \mathrm{~h}^{-1}$. The $F Y-3 B$ MWRI precipitation retrieval data used in this study are the level 2 products stored in Hierarchical Data Format (HDF), version 5. In addition to the retrieved precipitation rate, information on the pixel scan position and geographic location for each FOV is also included in the level 2 data files and decoded for use in this study.

\section{c. Parallax correction for the FY-3B level 2 rain-rate retrievals}

A common practice in generating level 2 products from low-Earth-orbiting (LEO) PMW measurements, rain-rate retrieval for an $F Y$-3B MWRI FOV is allocated 

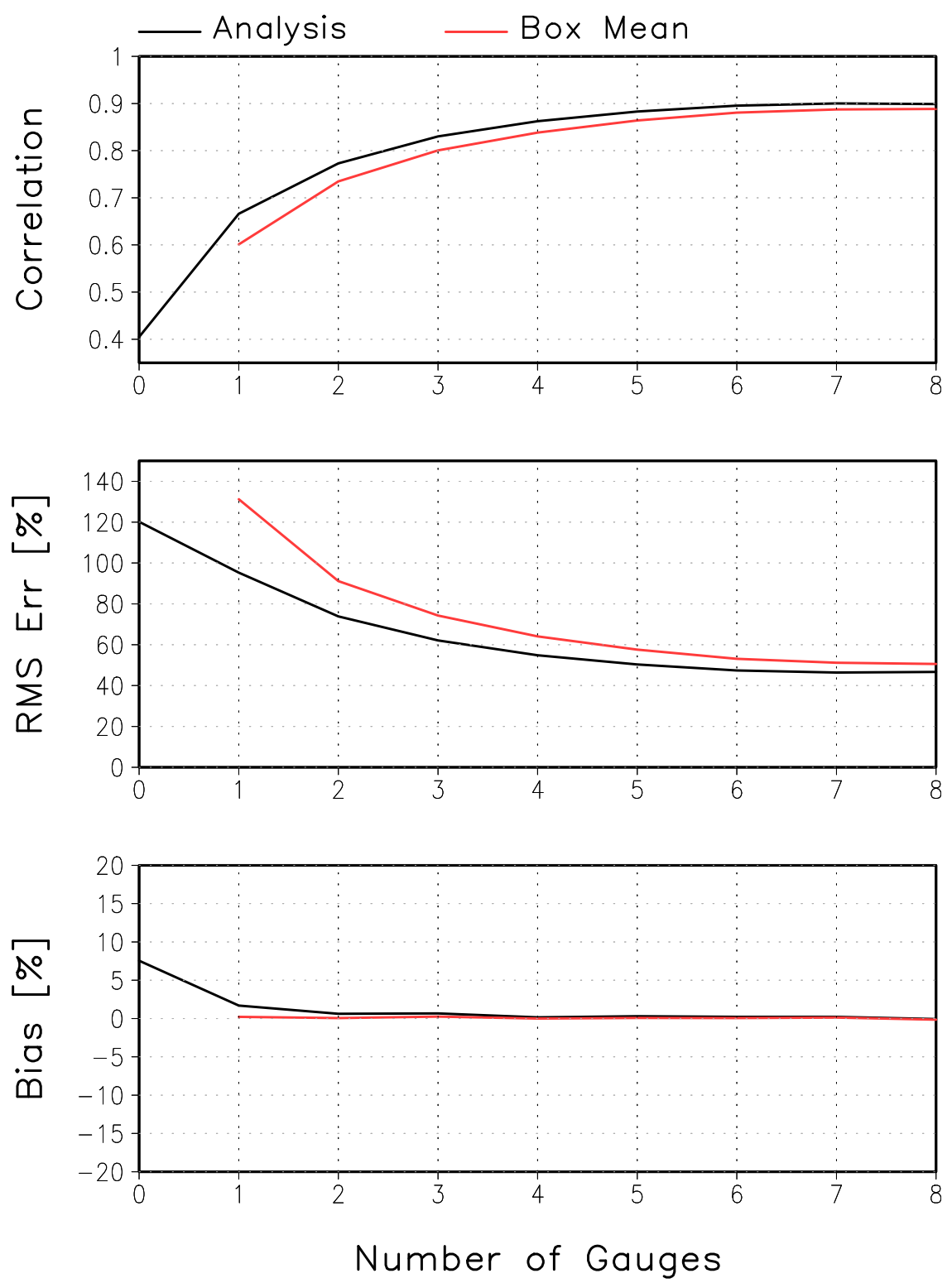

FIG. 4. As in Fig. 3, but for the gridbox mean (red) and gauge analysis (black) of 5-min rain rate.

to a geographical location (latitude and longitude) determined through calculations assuming that the satellite sensor is looking at the earth's surface. This assumption introduces errors in the calculated FOV positions when the sensor is facing a cloud of a certain height. The displacement between the calculated and real positions of a cloudy FOV is a function of the satellite evaluation angle and the height of the precipitating particles observed by the satellite (Wang et al. 2011) and may reach to the magnitude of a single cloud cell $(>10 \mathrm{~km})$. Parallax correction needs to be conducted to position the target FOV on its real location for applications of high-resolution satellite products (Joyce et al. 2001; Vicente et al. 2002; Liu et al. 2008; Wang et al. 2011).
As a part of this work, a comparative study is performed to examine the quantitative effects of the parallax correction to the evaluation of $F Y$-3B PMW level 2 retrievals of instantaneous rain rates at their FOVs. To this end, a set of procedures are developed to determine the real position (latitude and longitude) of a cloudy FOV from the satellite elevation angle, the position of subsatellite point, the cloud-top height, and the nominal position of the FOV determined without consideration of the cloud-top height, following equations describing the satellite scanning geometrics under a spherical coordinate (see the appendix). As clearly shown by Eq. (A1) in the appendix, the parallax displacement is proportional 
to the cloud-top height and the cotangent of the satellite elevation angle. This means that the displacement is about 1.3 times the cloud-top height for an $F Y$ - $3 B$ FOV with an elevation angle of $\sim 37^{\circ}$.

Since the $F Y-3 B$ MWRI takes a conical scan mode, the satellite elevation angle is a constant for FOVs at all scan positions. The real position of an FOV can therefore be calculated from the position of the subsatellite point, the cloud-top height, and the nominal position of the target FOV. Information on the nominal FOV position is included in the $F Y-3 B$ level 2 product package and is used in this study for parallax correction. The position of the subsatellite point is determined for each scan of the $F Y-3 B$ FOVs assuming that the scan is part of a circular arc. The cloud-top height for an FOV is determined as follows. First, a fixed cloud height of $8 \mathrm{~km}$ is used to get an estimated position for the FOV. Cloudtop temperature at that position is then achieved from the full-resolution $(4 \mathrm{~km} \times 4 \mathrm{~km})$ global composite GEO infrared (IR) brightness temperature data of the NOAA Climate Prediction Center (CPC; Janowiak et al. 2001). This GEO IR-based cloud-top temperature is then converted to cloud height through the vertical atmospheric temperature profile at the location and for the satellite observation time derived from the NOAA National Centers for Environmental Prediction (NCEP) Climate Forecast System Reanalysis (CFSR; Saha et al. 2010). Parallax-corrected FOV position is finally calculated through the equations derived in the appendix.

To examine the effects of this parallax correction, $F Y-3 B$ level 2 rain-rate retrievals are compared against the gauge analysis of 5-min rainfall centered at the satellite observation time over a circular area of $\sim 25 \mathrm{~km}$ in diameter centered at the FOV positions before and after the correction. Figure 5 illustrates cross sections of $F Y-3 B$ rain-rate retrievals $\left(\mathrm{mm} \mathrm{h}^{-1}\right)$, as well as mean gauge rainfall over FOVs centered at positions before and after the parallax correction, along a selected scan line over northern China around 1800 UTC 8 July 2012. Without the parallax correction, the pattern of the satellite retrievals presents a substantial deviation from the gauge observations. The shift of the maximum rain-rate position in the uncorrected $F Y-3 B$ is quite common (not shown). The rain-rate profile for the $F Y-3 B$ retrievals matches very closely with that for the gauge analysis after the parallax correction.

Results for a quantitative comparison between the $F Y-3 B$ retrievals and the gauge rainfall at $F O V$ locations are shown in Fig. 6. The agreement between the $F Y-3 B$ retrievals and the gauge rainfall improves with the number of reporting gauges inside an FOV, reaching a stable level when measurements from five or more gauges are available for the definition of the ground

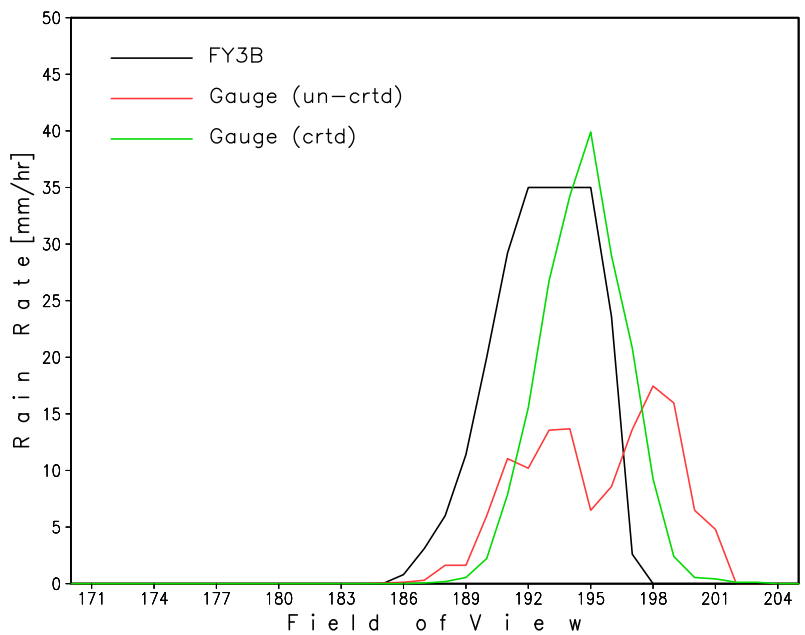

FIG. 5. Cross section of rain rates $\left(\mathrm{mm} \mathrm{h}^{-1}\right)$ of $F Y-3 B$ level 2 retrievals along a selected $F Y-3 B$ scan line over northern China, around $1800 \mathrm{UTC} 8 \mathrm{Jul} 2012$, together with gauge analysis of 5-min rain rates at the corresponding $F Y-3 B$ FOV positions determined with (green) and without (red) parallax correction. The $x$ axis indicates the FOV position. Distance between two neighboring FOVs is about $7 \mathrm{~km}$.

truth, consistent with results shown in Figs. 3 and 4 on the gauge analysis quality.

Understandably, effects of parallax correction become increasingly clear for FOVs with higher clouds and intensive rainfall. To examine the effects, correlation between the $F Y-3 B$ retrievals and the gauge analysis at locations determined with and without parallax correction is calculated as a function of cloud-top height and the retrieved rain rate at an FOV. The difference between the correlation before and after the parallax correction is larger than 0.1 for FOVs with cloud top of $12 \mathrm{~km}$ or taller (Fig. 7, top) and reaches $\sim 0.3$ for FOVs with very strong rainfall (Fig. 7, bottom). These results clearly demonstrate the necessity of parallax correction in evaluating PMW level 2 rain-rate retrievals at their FOV scale. Comparison of the satellite retrievals against the ground truth, either gauge observations or radar estimates, at the uncorrected FOV locations leads to substantially aliased performance statistics, especially for cases of tall clouds and heavy rainfall.

The height of the cloud used to perform the parallax correction described above is derived from satellite IR observations. This IR-based height is higher than that of ice particles and large water droplet concentrations observed by the PMW scattering channels and used by many techniques, including the one for $F Y-3 B$ to estimate precipitation over land. The parallax correction performed in this study would therefore yield overcorrection. The differences between the cloud top observed by IR and the effective height of ice particles/large water droplet 


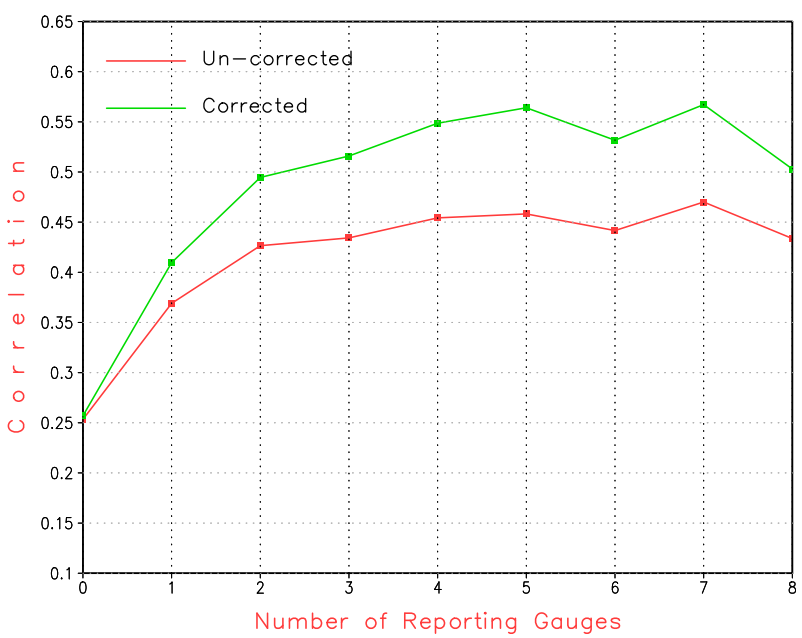

FIG. 6. Correlation between the gauge-analyzed 5-min rain rate and $F Y$-3B level 2 retrievals before (red) and after parallax correction (green) as a function of reporting gauges inside a satellite FOV.

concentrations observed from a PMW instrument, however, varies from cloud to cloud. It is extremely difficult to quantify the differences on a case by case basis with information available only from the IR and PMW observations for virtually all pixels. Preliminary experiments showed improved effects of the parallax correction using IR-based cloud-top height compared to that using a fixed cloud height $(8 \mathrm{~km})$ or using a cloud height with a fixed reduction $(20 \%)$ from that derived from the IR.

\section{Performance of $F Y-3 B$ level 2 rain-rate retrievals}

Based on the results of sections 2 and 3, performance of the $F Y$-3B MWRI level 2 rain-rate retrievals is examined through comparisons against gauge-based analyses averaged over a circular area of $25 \mathrm{~km}$ in diameter centering at the FOV position determined through the parallax correction. Although the level 2 retrievals are for instantaneous rain rate, gauge analyses of 5-min mean rain rate averaged over the satellite FOVs are utilized as the ground truth to smooth out the random error in the gauge data caused by the imperfect synchronizing of the gauge measurements among different stations and the delayed response of the tipping-bucket gauges in reporting light rainfall. To ensure reliable quality of the verification, only gauge data over an FOV with five or more reporting AWSs are included in the calculation of performance statistics to be discussed in this section. Following Tang et al. (2014), Kirstetter et al. (2014), and many other published studies, the $F Y-3 B$ level 2 retrievals are evaluated for their capacity in delineating raining cases, capturing intensive precipitation, and quantifying rainfall intensity, respectively.
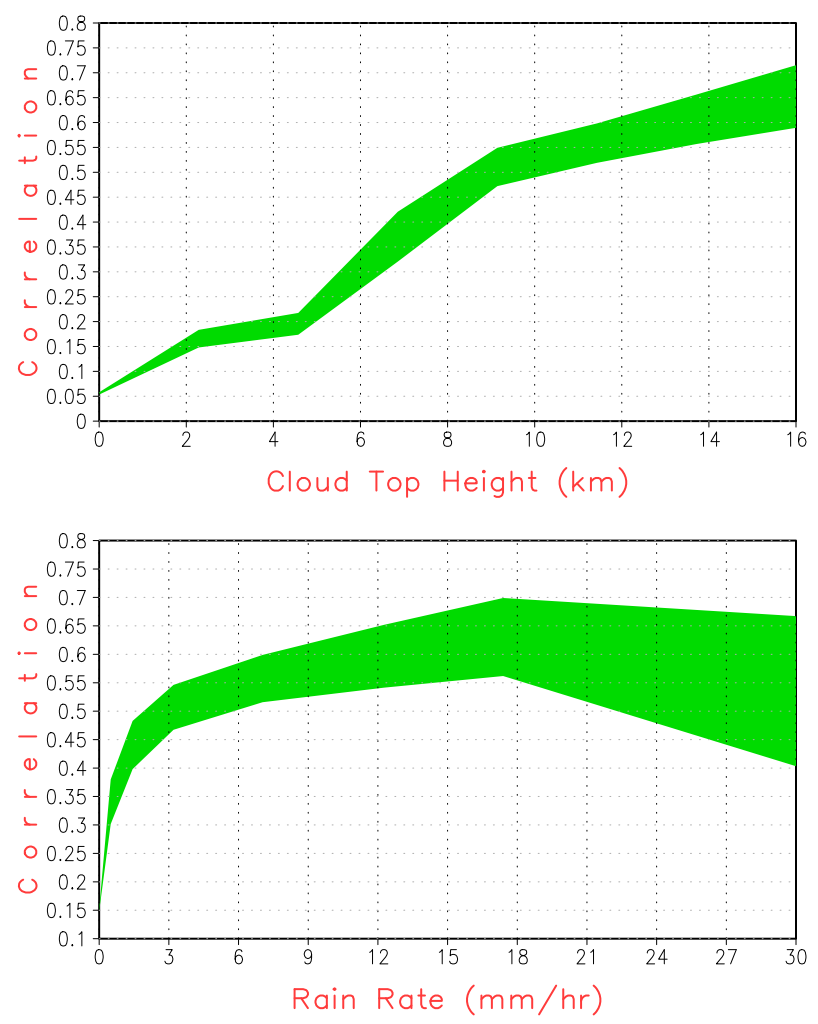

FIG. 7. Correlation between the gauge-analyzed 5-min rain rate and $F Y$ - $3 B$ level 2 retrievals before and after parallax correction, as a function of (top) cloud-top height $(\mathrm{km})$ and (bottom) rain rate $\left(\mathrm{mm} \mathrm{h}^{-1}\right)$. Correlations for the $F Y-3 B$ retrievals before and after the parallax are shown as the upper and lower parts of the shaded green belts, respectively. Only cases where/when reports from five or more gauges are available are used for the definition of the gauge analysis.

\section{a. Detecting raining and heavy rain events}

As described in section 3, the current operational version algorithm for the level $2 F Y-3 B$ rain-rate retrieval is composed of two consecutive steps, that is, to delineate raining cases and to quantify the rainfall intensity for the classified raining cases. Accuracy of the raining case detection is therefore fundamental to the overall retrieval performance. Three statistics are computed to evaluate the performance of the $F Y-3 B$ level 2 retrievals in detecting raining cases, including the probability of detection (POD), the false alarm rate (FAR), and the Heidke skill score (HSS). The POD is defined as the fraction of the cases when a raining FOV reported by the ground truth is detected by the satellite, while the FAR indicates the percentage of cases when the satellite classifies "no rain" cases as raining. The HSS is also utilized in this study to measure the overall capacity of the retrieval algorithm to identify raining cases against random chances, following Conner and Petty (1998) and Munchak and Skofronick-Jackson 

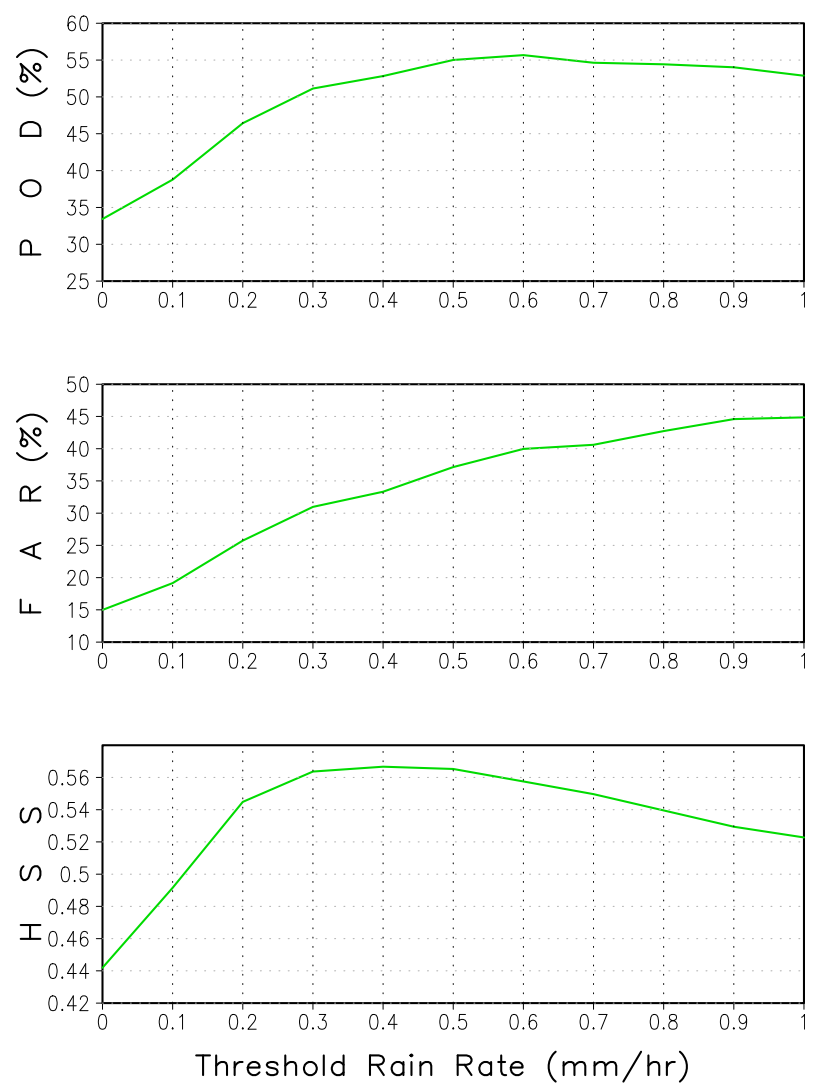

FIG. 8. (top) POD, (middle) FAR, and (bottom) HSS of the $F Y$-3B level 2 retrievals in delineating raining events, as a function of gauge-based threshold rain rate $\left(\mathrm{mm} \mathrm{h}^{-1}\right)$ to discriminate rain from no-rain cases.

(2013). Ranging from -1 to +1 , the HSS of positive (negative) values indicates a superior (inferior) skill of the algorithm compared upon random chance.

As a first step, sensitivity of the $F Y-3 B$ retrievals algorithm in detecting raining cases is examined using data over all eastern China for the entire data period of two warm seasons. The three statistics are computed to examine the performance of the algorithm in delineating raining cases with a combination of threshold intensities ranging from 0.0 to $1.0 \mathrm{~mm} \mathrm{~h}^{-1}$ (Fig. 8). The POD for detecting raining FOV improves from $\sim 34 \%$ for a threshold of $0.0 \mathrm{~mm} \mathrm{~h}^{-1}$ to $\sim 55 \%$ for a threshold of $0.5 \mathrm{~mm} \mathrm{~h}^{-1}$ and becomes stable for a higher threshold rain rate. The FAR, meanwhile, increases monotonically with the threshold rain-rate intensity, reaching as high as $45 \%$ for a threshold of $1 \mathrm{~mm} \mathrm{~h}^{-1}$. The HSS, a metric for the overall performance for raining detection, increases with the threshold intensity, reaches a maximum of $\sim 0.56$ for a threshold intensity of $0.3-0.5 \mathrm{~mm} \mathrm{~h}^{-1}$ before it degrades again for higher rain rates. This indicates that the current version of the $F Y-3 B$ level 2 retrieval algorithm is optimal to delineate raining cases at a sensitivity level of $\sim 0.4 \mathrm{~mm} \mathrm{~h}^{-1}$. Munchak and Skofronick-Jackson (2013) examined the performance of several PMW-based algorithms and found that a maximum HSS of $\sim 0.58(0.36)$ is achieved at a threshold of $0.3 \mathrm{~mm} \mathrm{~h}^{-1}\left(1.2 \mathrm{~mm} \mathrm{~h}^{-1}\right)$ in detecting precipitation over land for the AMSU/TMI-based retrievals, respectively (see their Fig. 7).

The $F Y-3 B$ rainfall detection skill exhibits systematic regional variations over eastern China (Fig. 9). All of the three performance metrics, the POD, FAR, and the HSS, present an increasing trend from the southeast toward the northwest portions of the examination domain. This variation pattern of the raining detection skill is attributable largely to the differences in the capacity of the $F Y-3 B$ retrieval algorithm to detect rainfall of varying characteristics. Warm season precipitation over southern China (the southeastern portion of the domain) is dominated by scattered convective systems, while that over northern China (the northwestern portion of the domain) is more often caused by synoptic systems of larger spatial scales. As a result, the standard deviation of the cloud-top temperature at 4-km pixels inside an FOV (Fig. 9, bottom right) presents regional variations very similar to those of the detection skills, suggesting that relatively low detection skill over southern China is associated with the limited capacity of $F Y-3 B$ retrievals in delineating rainfall from small systems inside an FOV. Munchak and SkofronickJackson (2013) and Kirstetter et al. (2014) both pointed out that the precipitation detection skills for PMW retrieval algorithms improve with the fraction of raining area inside the FOV. Further work is desirable to explore this association for the $F Y-3 B$ retrievals when radar estimates of precipitation are available to the authors.

Also investigated is the skill for the $F Y-3 B$ retrievals to capture severe storms of intensive precipitation. Toward this, performance statistics are computed for a combination of threshold rain-rate intensities, from 15 to $35 \mathrm{~mm} \mathrm{~h}^{-1}$, using data over the entire domain and for the entire period (Fig. 10). The POD is quite stable at a level of $\sim 35 \%$ in detecting heavy rain storms of medium intensity, but falls to zero for cases of heavy rainfall intensity $\left(>35 \mathrm{~mm} \mathrm{~h}^{-1}\right)$, caused apparently by the upper limit of the $F Y-3 B$ retrieved rain rate as described in section 3. The FAR increases with the threshold intensity of heavy rainfall, reaching $90 \%$ for the detection of intensive rainfall events with a rain rate of $35 \mathrm{~mm} \mathrm{~h}^{-1}$ or higher. Overall, the current version of the $F Y-3 B$ level 2 retrieval algorithm present reasonable skills, as measured by the HSS, in capturing heavy rainfall of medium intensity $\left(15-35 \mathrm{~mm} \mathrm{~h}^{-1}\right)$, but is unable to capture heavy rainfall of extreme intensity $\left(>35 \mathrm{~mm} \mathrm{~h}^{-1}\right)$. 

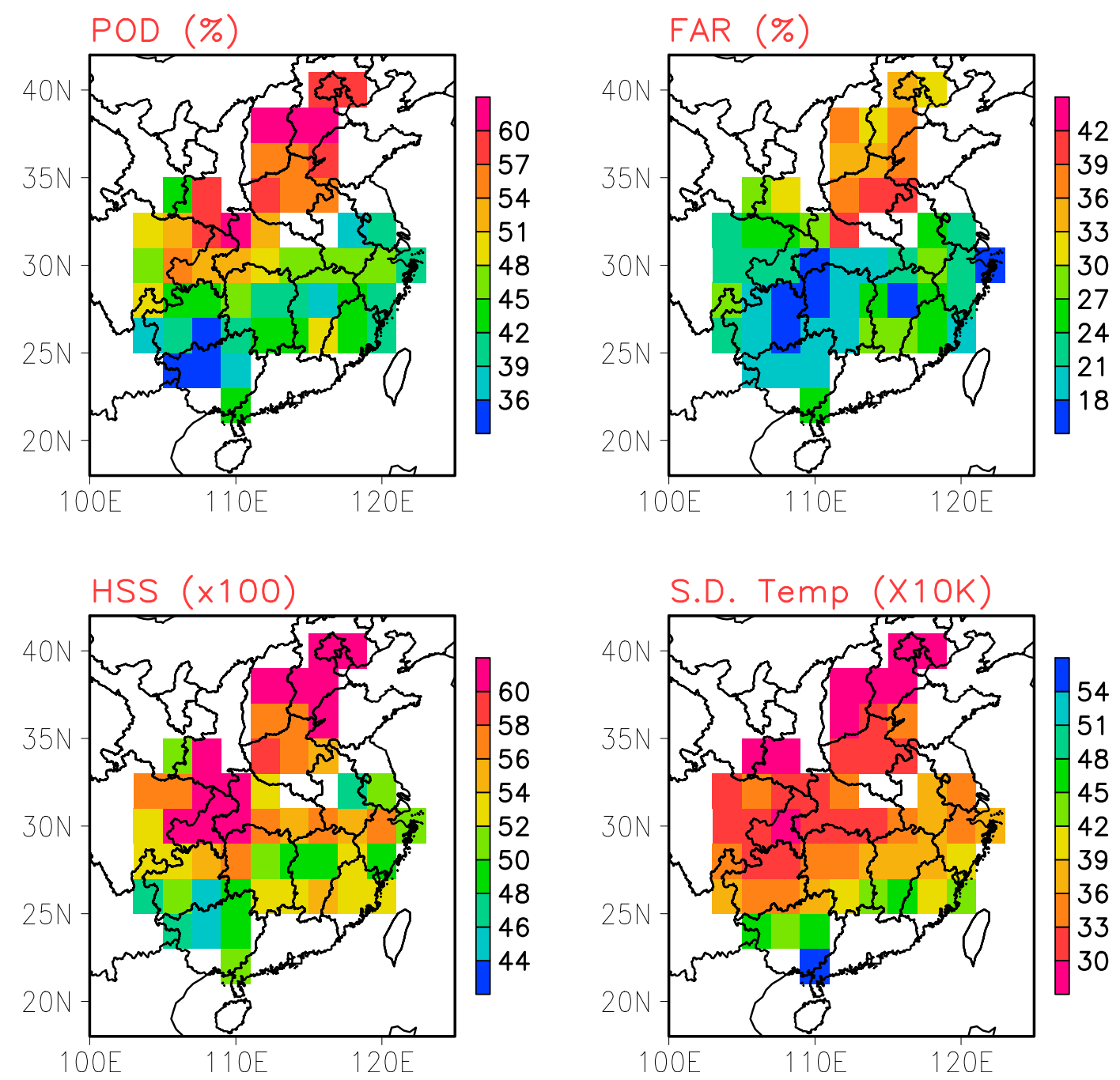

FIG. 9. Spatial distribution of the (top left) POD, (top right) FAR, and (bottom left) HSS of the $F Y-3 B$ level 2 retrievals in delineating raining events $\geq 0.2 \mathrm{~mm} \mathrm{~h}^{-1}$, together with (bottom right) the standard deviation of cloudtop temperature $(0.1 \mathrm{~K})$ for raining cases determined by the gauge-based analysis of 5 -min mean rain rate.

\section{b. Quantifying rain rate}

$F Y-3 B$ retrievals of instantaneous rain rate at their respective FOVs are compared against a time-space collocated gauge analysis of 5-min rain rate using data over the entire domain and for the entire study period of the 2012 and 2013 warm seasons. A two-dimensional histogram of the gauge rainfall and satellite retrievals is constructed (Fig. 11, top) to examine the performance of the $F Y-3 B$ level 2 retrievals. Only data for FOVs with five or more reporting gauges are included in the examination to ensure reliable results. The two-dimensional histogram exhibits a relatively concentrated distribution along the diagonal line (Fig. 11, top), indicating a good skill of the current version $F Y-3 B$ retrievals in representing the warm season rainfall intensity variations over eastern China. As already shown in Fig. 6, the correlation between the $F Y-3 B$ retrievals and the gauge analysis is approximately 0.55 . This correlation for $F Y-3 B$ retrievals is slightly lower than those reported in prior studies for retrievals from other satellite sensors. For example, Tang et al. (2014) achieved a correlation of $\sim 0.68$ for retrievals of warm season precipitation over the continuous United States (CONUS) from PMW imagers. Direct comparison of the correlation coefficients from these two studies may be misleading because 1) the target precipitation fields are different and 2) the ground truth data are different. While gauge analysis based on a station network of less-than-desirable density suffers from sampling error, radar estimates contain uncertainties of various magnitudes as well, caused by the inaccurate rain rate-reflectivity equations and the uncertain relationship 

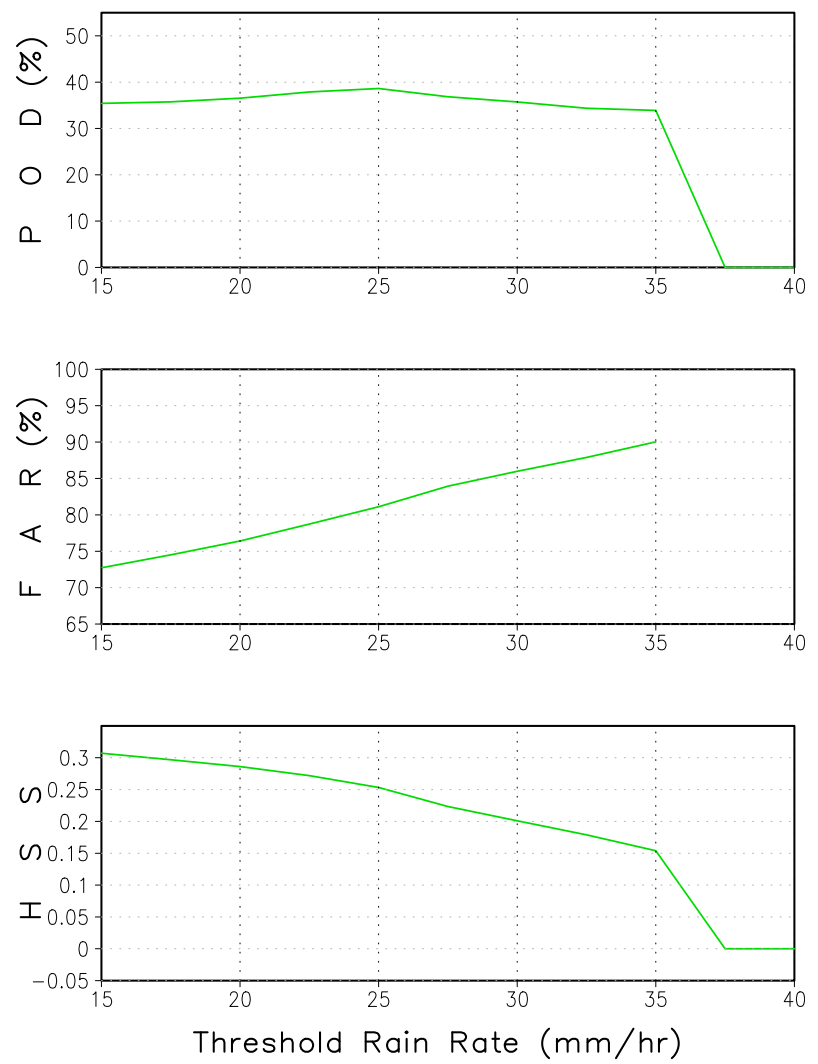

FIG. 10. As in Fig. 8, but for delineating heavy rain events, as a function of gauge-based threshold rain rate $\left(\mathrm{mm} \mathrm{h}^{-1}\right)$ used to define the heavy rain cases.

between the droplet concentration inside the cloud and the rainfall intensity on the ground. Future work of a gauge-radar-satellite three-way comparison over a region of very dense station network may provide more comprehensive assessments of the satellite retrievals.

The $F Y-3 B$ retrievals tend to overestimate for light rainfall cases, producing a relatively large density pattern slightly above the diagonal line for a gauge-based rain rate of $0-2 \mathrm{~mm} \mathrm{~h}^{-1}$ (Fig. 11, top). In the meantime, as already discussed in the previous subsection, the $F Y-3 B$ retrievals have an upper limit of $35 \mathrm{~mm} \mathrm{~h}^{-1}$, unable to detect any heavy rainfall stronger than that threshold. The cases classified as no rain by the current $F Y-3 B$ algorithm (Fig. 11, bottom) are worth future discussion. While $91.58 \%$ of the cases set as no rain by the satellite algorithm are correct, $8.42 \%$ of the cases are raining as determined from the gauge observations, with an FOV mean rain rate reaching $20 \mathrm{~mm} \mathrm{~h}^{-1}$ or higher. A detailed examination of those incorrectly classified raining cases may help improve the retrieval algorithm.

One important aspect of a satellite precipitation product's assessment is to examine the fidelity of the probability density function (PDF) for the retrieved and
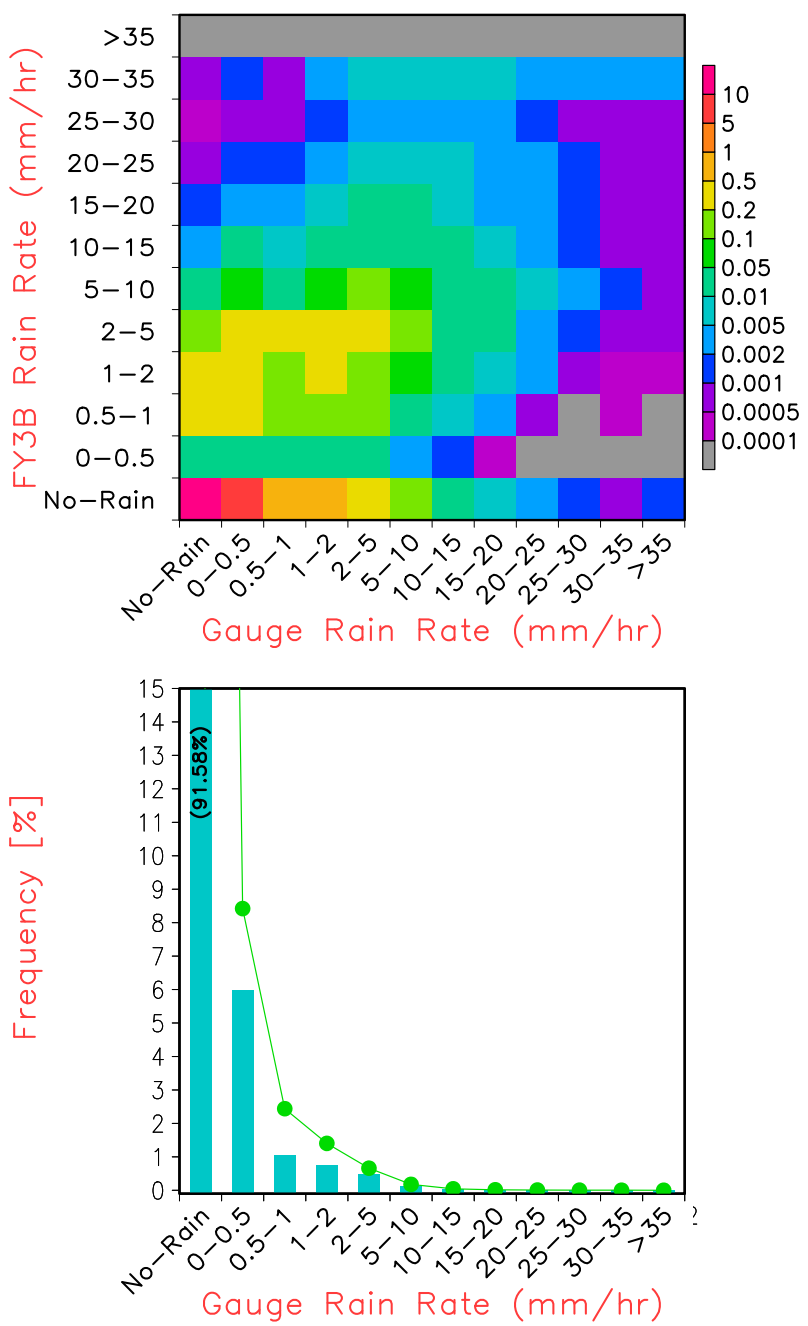

FIG. 11. (top) Two-dimensional histogram (\%) of the gaugemeasured 5-min mean rain rate ( $x$ axis) over the satellite FOV and the $F Y-3 B$ level 2 retrievals ( $y$ axis), as well as (bottom) the frequency of gauge-measured 5-min mean rain rate at different intensities for the no-rain cases indicated by the $F Y-3 B$ level 2 retrievals.

observed rain rates. In this study, cumulated PDF (CPDF) tables are constructed using collocated $F Y-3 B$ retrievals and gauge analysis data. Rain rates at various percentiles $(1 \%, 2 \%, \ldots, 98 \%, 99 \%)$ are computed for the $F Y-3 B$ and the gauge data and compared to each other (Fig. 12). The CPDF for the gauge analysis appears as a continuous curve, intersecting with the vertical line of $0 \mathrm{~mm} \mathrm{~h}^{-1}$ at $87.95 \%$. The CPDF for the $F Y-3 B$ retrievals, meanwhile, presents a discontinuity at the percentile of $95.26 \%$ when the rain rate drops from $0.2 \mathrm{~mm} \mathrm{~h}^{-1}$ (the designed retrieval sensitivity) to zero (Fig. 12, top). Frequency of the no-rain cases is about $7.3 \%$ higher in the $F Y-3 B$ retrievals than that in the gauge observations. The percentile rain rates in the $F Y-3 B$ are higher (lower) than 

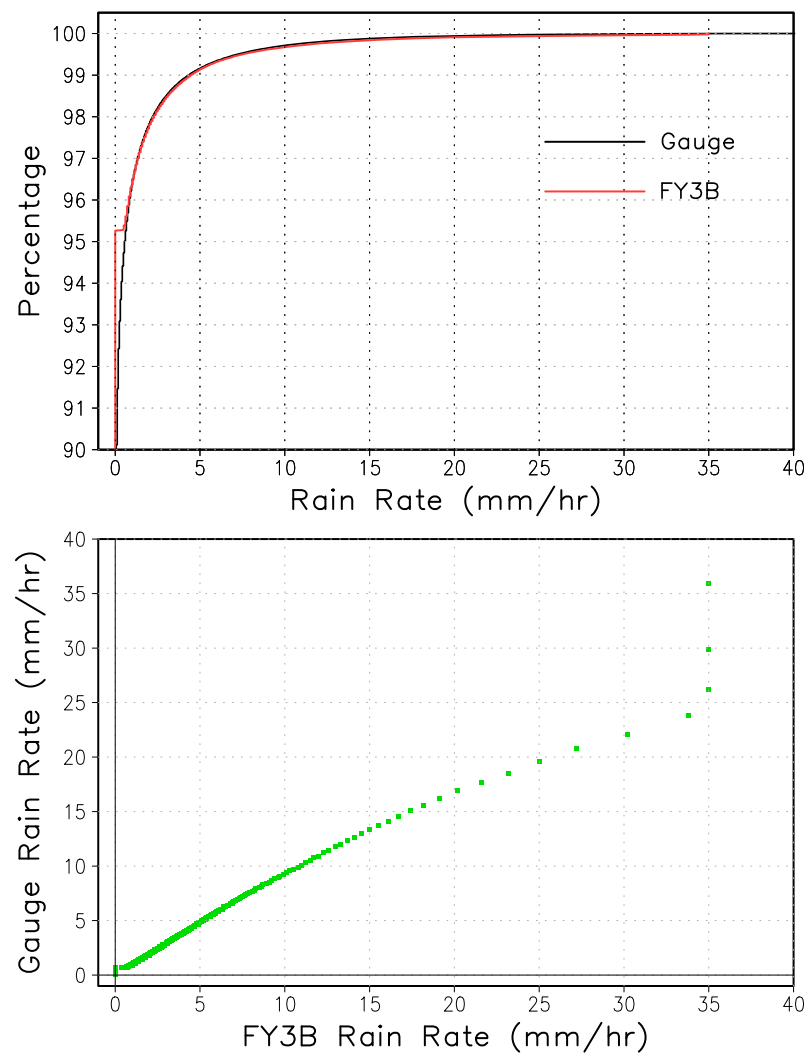

FIG. 12. (top) Accumulated PDF (\%) of the $F Y-3 B$ level 2 retrievals (red) and the gauge-measured 5-min mean rain rate (black). (bottom) Scatterplots between the rain-rate values at 1st, 2nd, .., 98th, and 99th percentiles from the $F Y$-3B level 2 retrievals ( $x$ axis) and the gauge-based analysis ( $y$ axis).

those in the observations for heavy (light) rainfall (Fig. 12, bottom), indicating intensity-dependent bias structure in the satellite-retrieved precipitation products.

To further explore this intensity dependency of the satellite rainfall performance, quantitative evaluations are conducted for the $F Y-3 B$ retrievals for cases of different rainfall intensities (Fig. 13). Collocated satellite and gauge data are stripped into 12 groups according to the intensity defined by the gauge-based analysis ( $x$ axis). A group of cases with gauge measured rain rate higher than $35 \mathrm{~mm} \mathrm{~h}^{-1}$ is included to examine how these heavy rainfall cases are captured by the $F Y-3 B$ retrievals. Correlation between the $F Y-3 B$ retrievals and the gauge analysis increases with the rainfall intensity, from less than 0.4 for cases of rain rate less than $2 \mathrm{~mm} \mathrm{~h}^{-1}$, to higher than 0.8 for cases of rain rates stronger than $30 \mathrm{~mm} \mathrm{~h}^{-1}$. The relatively low correlation for weak rainfall is attributable to multiple factors. As discussed in section 2, gauge observation accuracy is less than desirable because of the delay of the tipping-bucket gauges in reporting light rainfall. At the meantime, PMW retrievals of light rainfall are also compromised by
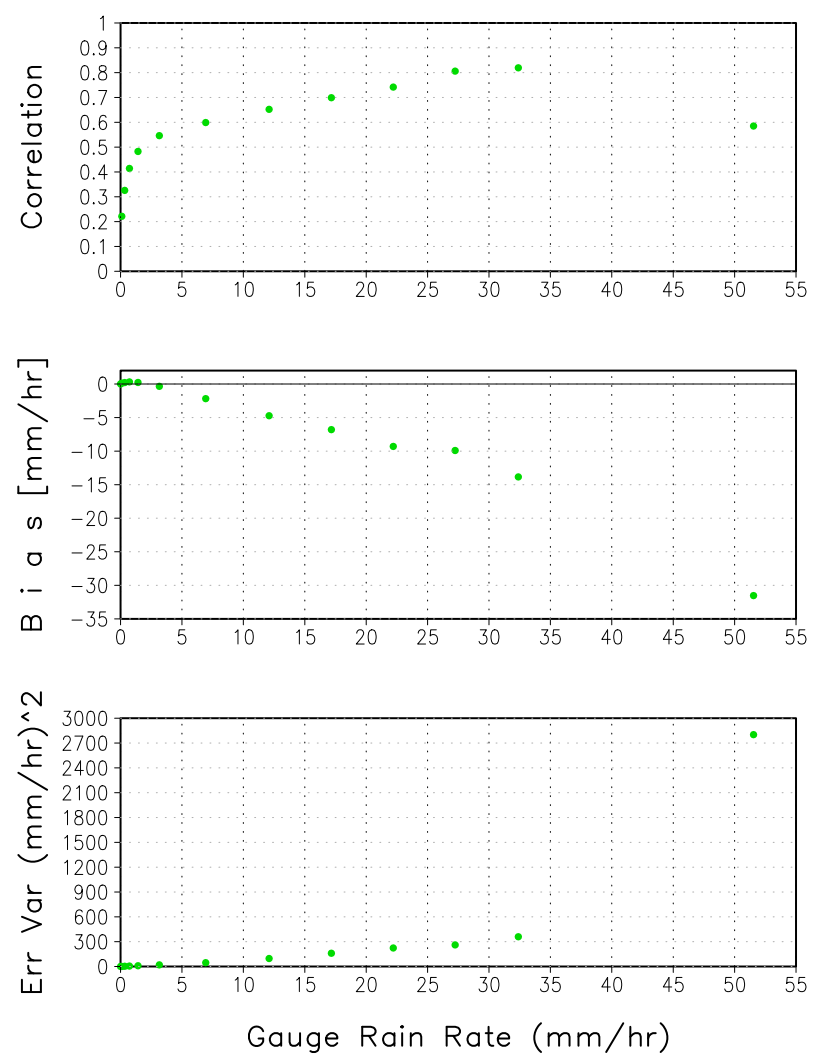

FIG. 13. Performance of the $F Y-3 B$ level 2 retrievals as a function of rain rate determined by the gauge analysis. (top) Correlation, (middle) bias $\left(\mathrm{mm} \mathrm{h}^{-1}\right)$, and (bottom) error variance $\left[\left(\mathrm{mm} \mathrm{h}^{-1}\right)^{2}\right]$ calculated through comparison against the gauge-based analysis of 5 -min mean rain rate.

the low and/or small clouds inside the FOVs (Kummerow et al. 2006; Munchak and Skofronick-Jackson 2013; Kirstetter et al. 2014). Correlation declines sharply for cases of rain rate stronger than $30 \mathrm{~mm} \mathrm{~h}^{-1}$, caused apparently by the upper limit of $35 \mathrm{~mm} \mathrm{~h}^{-1}$ set for the $F Y-3 B$ retrievals.

Bias for the $F Y-3 B$ level 2 retrievals, calculated for each of the 12 groups as the mean difference $\left(\mathrm{mm} \mathrm{h}^{-1}\right)$ against the collocated gauge analysis, is positive (negative) for cases of rain rate higher (lower) than $2 \mathrm{~mm} \mathrm{~h}^{-1}$ (Fig. 13, middle). Although positive bias for light rainfall cases is very small (usually less than $0.2 \mathrm{~mm} \mathrm{~h}^{-1}$ ), frequent occurrence of the cases accumulates the bias to overestimation of substantial magnitude, compensating the underestimates for heavy rainfall. The random error variance (Fig. 13, bottom) increases with the rain-rate intensity, following approximately a linear trend as assumed in prior studies on satellite precipitation retrieval error (e.g., Huffman 1997; Xie and Xiong 2011). Error variance for rain rates larger than $30 \mathrm{~mm} \mathrm{~h}^{-1}$ appears as an outlier, again as a consequence of the upper limit set for the $F Y-3 B$ retrieved rainfall. 

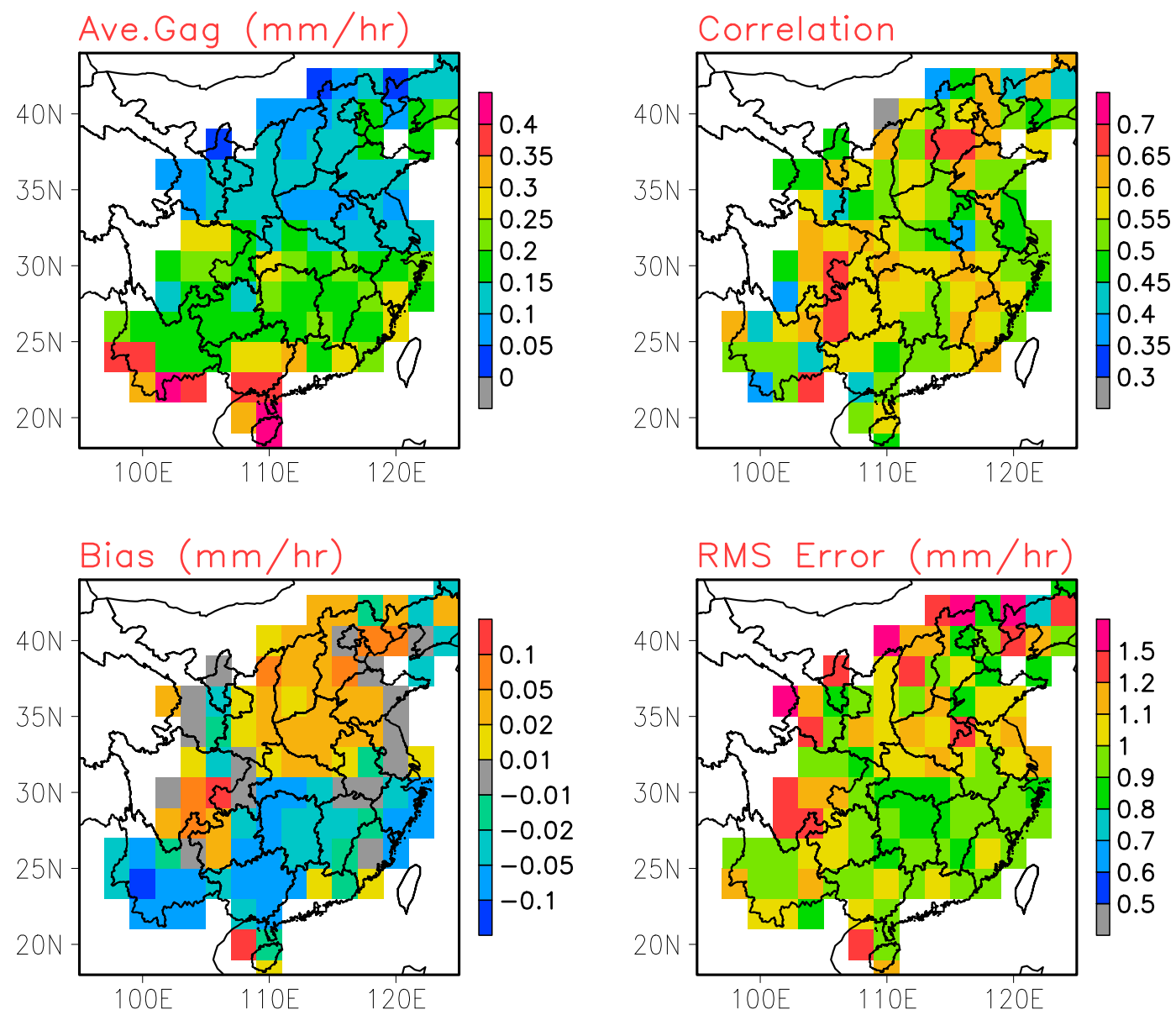

FIG. 14. (top left) Spatial distribution of gauge-based analysis averaged over the entire data period $\left(\mathrm{mm} \mathrm{h}^{-1}\right)$ and the (top right) correlation, (bottom left) bias $\left(\mathrm{mm} \mathrm{h}^{-1}\right.$ ), and (bottom right) RMS error compared against the gaugebased analysis of 5-min mean rain rates. The calculations are performed using data over FOVs with five or more reporting gauges over the entire data period. RMS error is in fractions of the standard deviation of the gauge rainfall.

Performance of the $F Y-3 B$ retrievals presents regional variations (Fig. 14). Overall, the $F Y-3 B$ retrievals tend to underestimate (overestimate) precipitation over southern (northern) China. The correlation [root-mean-square (RMS) error] exhibits a decreasing (increasing) trend from south toward the north, although not as clear as that for the bias. Examinations using data for a longer period may yield more distinct regional patterns of the performance statistics.

Gauge-based analyses over seven selected urban regions are utilized in this study to examine the performance of the $F Y-3 B$ retrievals taking advantage of the high-density AWS gauge networks there. PMW precipitation retrievals over urban areas, however, might be compromised sometimes because of the microwave signals influenced by the geography and the architectures on the ground. The performance of the $F Y-3 B$ shown in this work therefore might be underestimated for regions without these urban microwave influences. However, brief inspections of the $F Y-3 B$ retrievals as part of the evaluation process did not show outliers of ridiculous magnitude, implying that the influences might be of minor magnitude in most cases and the examination results are representative of the $F Y-3 B$ retrieval performance for most regions over China.

\section{c. Performance over different portions of a cloud system}

Many applications of the satellite precipitation products, such as those in the field of hydrologic modeling and prediction, require accurate documentation of rainfall distribution inside an individual weather system. Evaluation of the satellite precipitation retrievals therefore need to be conducted for various portions of a cloud system. In this study, performance of the $F Y-3 B$ retrievals is assessed in relation to the distance from the target FOV at the center of a storm. 
First, $F Y-3 B$ scan lines with five or more consecutive raining pixels are selected through checking on the gaugeanalyzed rainfall amount over the corresponding FOVs along the scan line. FOV with the maximum gauge-based rainfall is then identified and set as the "center" of the rain storm. Profiles of the $F Y-3 B$ retrievals, gauge-based rainfall, and the GEO-observed cloud-top temperature are consequently composited relative to the position of the storm center using data from all selected raining scan lines over eastern China for the two warm seasons of 2012 and 2013. Profiles for gauge-based analyses of 1-, 5-, and 60-min mean rainfall are included for comparison purposes. These profiles are constructed for ascending and descending orbits separately to examine the rainfall distributions in the afternoon and morning, respectively. Profiles along the scan lines roughly represent the storm structure along the east-west direction because of the $F Y-3 B$ scan direction over China. Although an $F Y-3 B$ MWRI is about $25 \mathrm{~km}$ in diameter, the distance between two neighboring FOVs is approximately $7-8 \mathrm{~km}$ because of the overlapping between FOVs along a scan line. Since the distance between two neighboring $F Y-3 B$ FOVs is $\sim 7 \mathrm{~km}$, this selection excludes any storms smaller than $35 \mathrm{~km}$ in their cross section and avoided the inclusion of scans across the edge of a cloud system.

The $F Y-3 B$ retrievals capture the overall east-west distribution pattern of a storm quite well (Fig. 15). The retrievals, however, tend to underestimate the heavy rainfall at the storm center as determined by the maximum gauge analysis while overestimating the precipitation at both edges of a storm. In the morning (descending orbits), position of the maximum $F Y-3 B$ retrievals matches quietly closely with that of the gauge analysis (Fig. 15, bottom). In the afternoon, however, the maximum $F Y-3 B$ retrievals are shifted by one FOV, or about $7-8 \mathrm{~km}$ toward the leeward direction, compared to that for the gauge observations. The position of the maximum retrievals, however, matches closely with that of the maximum cloudiness for both the ascending and descending orbits. The leeward shift of the maximum retrievals relative to the maximum surface rainfall in the afternoon is therefore a reflection of the disposition between the maximum cloudiness and rainfall. Since PMW retrievals of land precipitation rely heavily on the scattering signals from ice particles and large water droplets inside a cloud, the overlapping (leeward shift) of the retrieved maximum rainfall in the descending (ascending) orbits is most likely attributable to the structure and evolution of a precipitating cloud system, as reported by early work such as Browning et al. (1973) and Hobbs (1978).

An accurate investigation of a precipitating cloud system requires the examination of structures on a twodimensional domain with consideration of local wind
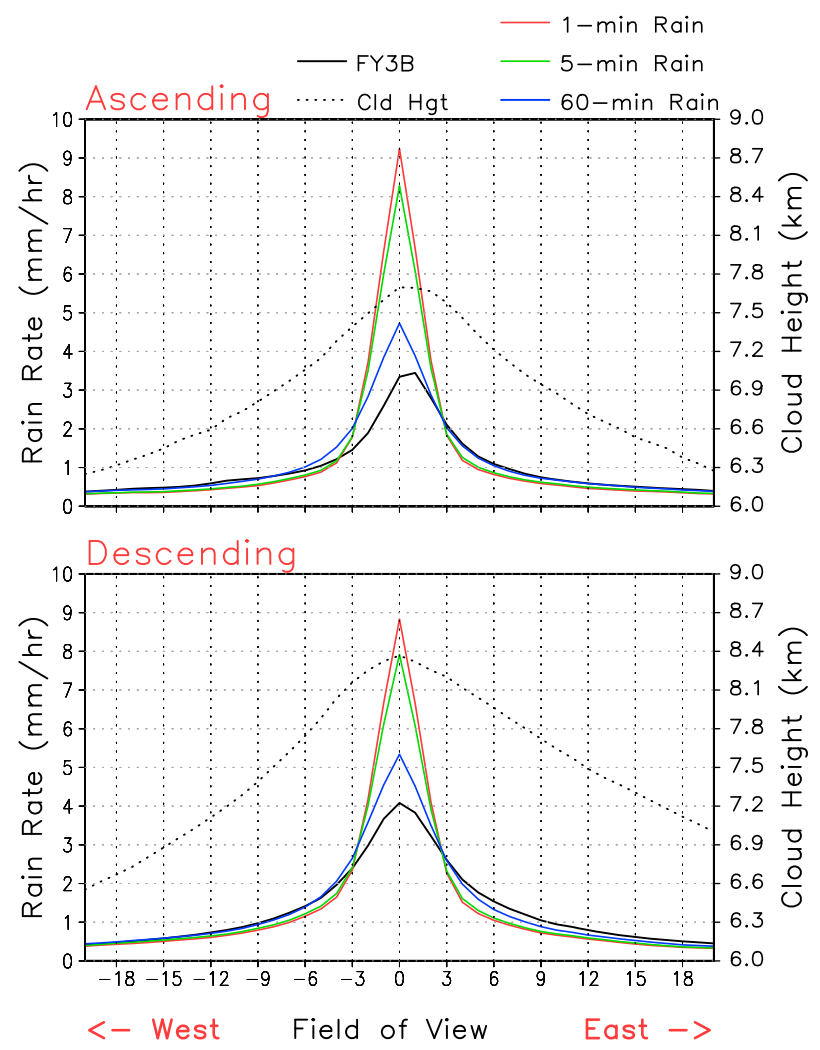

FIG. 15. Cross section of $F Y-3 B$ level 2 retrievals (solid black) and gauge-based rain rates of 1-(red), 5- (green), and 60-min (blue) mean rain rates, as well as the cloud-top height (dotted black) along an $F Y-3 B$ scan line. The mean values are computed for FOVs of different positions relative to the FOV of maximum rain rate determined by the gauge analysis ( $x$ axis), using data for the entire data period of this study.

impacts. Here, as a first step, we decided to examine the cloud/precipitation only in one dimension, along the scanning direction of the $F Y-3 B$ MWRI. Fortunately, over China the $F Y-3 B$ MWRI scanning is mostly along the eastwest direction, which is the primary direction of cloud system development and movements. We have chosen to only select cloud systems with five or more continuous raining pixels to focus on those of meso or larger spatial scales. Further work examining the three-dimensional structure of a precipitating cloud system using gauge measurements, ground-based/spaceborne radars, and satellite PMW and IR observations may provide insights on how PMW retrievals may be improved in accurately quantifying the precipitation structures (Kummerow et al. 2014).

\section{Summary and conclusions}

Level 2 rain-rate retrievals from the Microwave Radiation Imager (MWRI) on board the Chinese FengYun $(F Y)$ $3 B$ satellite were evaluated using gauge measurements of minute rainfall from a dense network of automatic weather 
stations (AWSs) over eastern China. First, a set of experiments were conducted to examine the quality of the AWS gauge-based analysis, and the results showed that a minimum of five reporting gauges are needed inside the target $F Y-3 B$ FOV of approximately $25 \mathrm{~km}$ in diameter to ensure a high accuracy of the gauge analysis to be used as the ground truth. Gauge-based analyses of 1-min rainfall were then constructed on a $0.05^{\circ}$ latitude-longitude grid over eastern China for the warm seasons (May-September) of 2012 and 2013 through interpolation of qualitycontrolled gauge reports from over 30000 stations.

Meanwhile, parallax correction was performed to determine the real position for $F Y-3 B$ satellite field of view (FOV) with consideration of nonzero cloud height. Ground truth for the $F Y-3 B$ level 2 retrievals of instantaneous rain rate was then defined as the 5-min mean rate centering at the corresponding FOV observation time and over all of the $0.05^{\circ}$ latitude-longitude grid boxes falling into the target $F Y-3 B$ FOV of $\sim 25 \mathrm{~km}$ in diameter. Quantitative examinations of the $F Y-3 B$ level 2 retrievals were finally conducted through comparisons against the gauge-based analyses of 5-min rainfall for the 2012 and 2013 warm seasons. Only gauge analyses with five or more reporting gauges inside an FOV are used as the ground truth to ensure reasonable quality.

The following conclusions can be drawn from the examination results of this study.

1) Parallax correction is crucial to ensure accurate evaluation and applications of the level 2 precipitation retrievals from $F Y-3 B$ and other low-Earth-orbiting (LEO) satellites, including the Global Precipitation Mission (GPM) core satellite. The spatial displacement caused by the parallax effects is proportional to the height of precipitating clouds and the cotangent of the satellite elevation angle, reaching to a magnitude of $10 \mathrm{~km}$ or larger for high clouds.

2) In general, the current version of the $F Y$ - $3 B$ level 2 retrievals presents good skills in detecting raining pixels and quantifying rain rate, with performance statistics similar to those for the retrievals from other PMW sensors. However, the $F Y-3 B$ retrievals tend to miss precipitation from warm and low cloud systems of small scales and underestimate (overestimate) heavy (light) precipitation. In particular, the maximum rain rate is saturated at a relatively low level of $35 \mathrm{~mm} \mathrm{~h}^{-1}$, yielding significant underestimation for many heavy rainfall events.

3) Maximum rainfall detected by the $F Y-3 B$ retrievals for the afternoon orbits is shifted by about $7-8 \mathrm{~km}$ toward the leeward direction, most likely caused by the displacement between the heavy rainfall and tallest cloud top.
In this work, as a first step, the height of precipitating clouds used to perform the parallax correction is the cloudtop height derived from satellite observations of the IR window channel, which is higher than the concentration of ice particles and large water droplets observed by the PMW channels and used to estimate precipitation over land. Ideally, the parallax correction should be performed as part of the level 2 retrievals with the effective cloud height derived from IR, PMW channel temperatures, and other information such as the vertical profiles of air temperaturemoisture and cloud-precipitation droplet concentration profiles (Kummerow et al. 2011). We strongly recommend that future PMW precipitation retrievals include parallax correction in determining the position for each satellite FOV.

An implicit assumption for the production and application of level 2 precipitation retrievals is that the retrievals are for the instantaneous precipitation rate at the moment of satellite observations. However, there is a delay of substantial magnitude from the time the precipitating particles (ice particles and large water droplets) inside a cloud are measured by a radiometer and the time these particles fall to the surface and are measured by a rain gauge. It is an important and interesting research topic to examine how much the delay is for different types of clouds and at different phases of cloud development. With the position of satellite FOV determined accurately after appropriate parallax correction, it becomes possible to explore the question using gauge measurements from a dense station network like that of the CMA AWS system. We hope we will have opportunity to work on these topics in the future.

Enhancing the temporal and spatial sampling of passive microwave satellite observations, level 2 retrievals from $F Y-3 B$ have been used as inputs to the reprocessed CMORPH. Preliminary results showed improved quality in the integrated precipitation estimates over the global regions. Further work is needed to improve our understanding of the level 2 PMW retrievals and to quantify their error structure. While the use of gauge measurements from a dense AWS network enabled the evaluation of the level 2 products with a direct measurement of rain rates, spatial sampling from an operational AWS network is still limited compared to that from radar observations, and the measurements are less accurate for light rainfall because of the delay in reporting from a tipping-bucket gauge. Combined use of the AWS network, the ground radar, and the spaceborne precipitation radar is worth exploring for the three-dimensional structure of the precipitating cloud systems and their association with satellite PMW level 2 precipitation retrievals.

Acknowledgments. The authors would like to express their thanks to Robert Joyce for his technical help in 
decoding the level 2 PMW retrievals during the early stage of this work and to Craig Long and Shaorong $\mathrm{Wu}$ for plotting some of the figures of this paper. The comments of Dr. C. Kummerow, Dr. Y. Tian, and three anonymous reviewers greatly helped improve the quality of the manuscript. This work is supported by the Youth S\&T Fund Project (Grant NMIC_QJ_ 201110 and NMIC_QJ_201210), R\&D Special Fund for Public Welfare Industry (meteorology) of China (Grants GYHY201306045, GYHY201206008, and GYHY201506002), International S\&T Cooperation Program of China (Grant 2011DFG23150), and Project Supported by National Natural Science Foundation of China (Grant 91437220).

\section{APPENDIX \\ Parallax Correction}

Unless otherwise stated, location of a satellite FOV, or a pixel, in a level 1 or level 2 satellite product package is determined by assuming that the target object of the satellite observation is at the spherical surface of the earth with an elevation of $0 \mathrm{~m}$. With a nonzero height, the real geographic position of a target, for example, clouds, will be different, located between the assigned location and the subsatellite point. The difference between the real and assigned positions of the target, called parallax displacement in distance $\Delta$ in this study, can be expressed as a function of the height $H$ of the target and the satellite elevation angle from the location of the $\operatorname{target} \theta$ :

$$
\Delta=\cot (\theta) H .
$$

Consider a triangle $\triangle \mathrm{ABC}$ connecting the north pole (A), the subsatellite point (B), and the assigned position of the target $(C)$ on the spherical surface of the earth (Fig. A1). Arcs AB $\gamma$ and AC $\beta$ can be defined as

$$
\gamma=\frac{\pi}{2}-\varphi_{s}
$$

and

$$
\beta=\frac{\pi}{2}-\varphi_{a},
$$

where $\varphi_{s}$ and $\varphi_{a}$ are the latitudes of the subsatellite point and that of the assigned position of the target, respectively. The angle between the arc $\mathrm{AB}$ and arc $\mathrm{AC}$, $\angle \mathrm{BAC}$, is the difference between the longitude of the subsatellite point $\lambda_{s}$ and that of the assigned position of the target $\lambda_{a}$ :

$$
\angle \mathrm{BAC}=\lambda_{s}-\lambda_{a}
$$

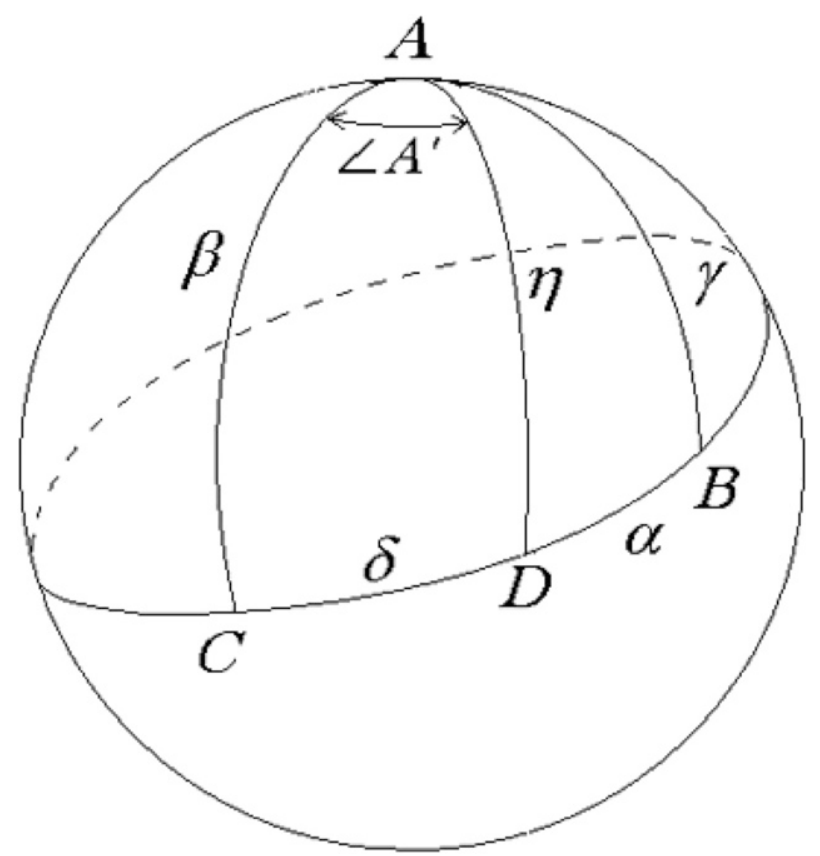

FIG. A1. Schematic illustration of satellite parallax correction under a spherical coordinate system. Points A, B, C, and D denote the north pole, the subsatellite point, and the nominal and real positions of a cloudy satellite FOV, respectively.

Using the sine rule of a spherical triangle, the angle between the arc $\mathrm{AC} \beta$ and $\operatorname{arc} \mathrm{BC} \alpha, \angle \mathrm{ACB}$, can be determined by

$$
\sin (\angle \mathrm{ACB})=\sin (\gamma) \sin (\angle \mathrm{BAC}) / \sin (\alpha)
$$

and

$$
\angle \mathrm{ACB}=\arcsin [\sin (\angle \mathrm{ACB})] .
$$

Now consider the spherical triangle $\triangle \mathrm{ADC}$ connecting the north pole (A), the real position of the target (D), and the assigned position of the target $(\mathrm{C})$ on the spherical surface of the earth (Fig. A1). The $\operatorname{arc} \mathrm{CD} \delta$ is the parallax displacement in radiance and can be calculated from the displacement in distance $(\Delta)$ and the earth radius $R_{e}$ :

$$
\delta=\frac{\Delta}{R_{e}}
$$

Following the cosine rule of a spherical triangle, the arc $\mathrm{AD} \eta$ can be derived by

$\cos (\eta)=\cos (\beta) \cos (\delta)+\sin (\beta) \sin (\delta) \cos (\angle \mathrm{ACB})$

and

$$
\eta=\arccos [\cos (\eta)]
$$


Angle DAC $\angle A^{\prime}$, meanwhile, can be determined using the sine rule:

$$
\sin \left(A^{\prime}\right)=\sin (\delta) \sin (\angle \mathrm{ACB}) / \sin (\eta)
$$

and

$$
A^{\prime}=\arcsin \left[\sin \left(A^{\prime}\right)\right] \text {. }
$$

The latitude $\varphi_{c}$ and longitude $\lambda_{c}$ for the real position of the target are

$$
\varphi_{c}=\frac{\pi}{2}-\eta
$$

and

$$
\lambda_{c}=\lambda_{a}+A^{\prime}
$$

As such, the real position of a target $\left(\varphi_{c}, \lambda_{c}\right)$ can be determined through the equations above from 1 ) the position of the subsatellite point $\left.\left(\varphi_{s}, \lambda_{s}\right), 2\right)$ the position of the assigned target position $\left.\left(\varphi_{a}, \lambda_{a}\right), 3\right)$ the height of the target, and 4) the satellite elevation angle from the target.

\section{REFERENCES}

AghaKouchak, A., A. Behrangi, S. Sorooshian, K. Hsu, and E. Amitai, 2011: Evaluation of satellite-retrieved extreme precipitation rates across the central United States. J. Geophys. Res., 116, D02115, doi:10.1029/2010JD014741.

Amitai, E., X. Llort, and D. Sempere-Torres, 2009: Comparison of TRMM radar rainfall estimates with NOAA next-generation QPE. J. Meteor. Soc. Japan, 87A, 109-118, doi:10.2151/jmsj.87A.109.

Browning, K. A., M. E. Hardman, T. W. Harrold, and C. W. Pardoe, 1973: The structure of rainbands with a mid-latitude depression. Quart. J. Roy. Meteor. Soc., 99, 215-231, doi:10.1002/ qj.49709942002.

Chen, M., W. Shi, P. Xie, V. B. S. Silva, V. E. Kousky, R. W. Higgins, and J. E. Janowiak, 2008: Assessing objective techniques for gauge-based analyses of global daily precipitation. J. Geophys. Res., 113, D04110, doi:10.1029/2007JD009132.

Conner, M. D., and G. W. Petty, 1998: Validation and intercomparison of SSM/I rain-rate retrieval methods over the continental United States. J. Appl. Meteor., 37, 679-700, doi:10.1175/1520-0450(1998)037<0679:VAIOSI >2.0.CO;2.

Creutin, J. D., and C. Obled, 1982: Objective analysis and mapping techniques for rainfall fields: An objective comparison. Water Resour. Res., 18, 413-431, doi:10.1029/WR018i002p00413.

Dai, A., X. Lin, and K. Hsu, 2007: The frequency, intensity, and diurnal cycle of precipitation in surface and satellite observations over low- and mid-latitudes. Climate Dyn., 29, 727 744, doi:10.1007/s00382-007-0260-y.

Ebert, E. E., J. E. Janowiak, and C. Kidd, 2007: Comparison of near-real-time precipitation estimates from satellite observations and numerical models. Bull. Amer. Meteor. Soc., 88, 47 64, doi:10.1175/BAMS-88-1-47.

Ferraro, R. R., and N. C. Grody, 1994: Effects of surface conditions on rain identification using the DMSP-SSM/I. Remote Sens. Rev., 11, 195-209, doi:10.1080/02757259409532265.
Gandin, L. S., 1965: Objective Analysis of Meteorological Fields. Israel Program for Scientific Translations, $242 \mathrm{pp}$.

Gopalan, K., N.-Y. Wang, R. Ferraro, and C. Liu, 2010: Status of the TRMM 2A12 land precipitation algorithm. J. Atmos. Oceanic Technol., 27, 1343-1354, doi:10.1175/2010JTECHA1454.1.

Grody, N. C., 1991: Classification of snow cover and precipitation using the Special Sensor Microwave/Imager (SSM/I). J. Geophys. Res., 96, 7423-7435, doi:10.1029/91JD00045.

Hobbs, P. V., 1978: Organization and structure of clouds and precipitation on the mesoscale and microscale in cyclonic storms. Rev. Geophys. Space Phys., 16, 741-755, doi:10.1029/RG016i004p00741.

Hong, Y., R. F. Adler, A. J. Negri, and G. J. Huffman, 2007: Flood and landslide applications of high-resolution satellite rainfall products. J. Nat. Hazards, 43, 285-294, doi:10.1007/ s11069-006-9106-x.

Hossain, F., and E. N. Anagnostou, 2004: Assessment of current passive-microwave- and infrared-based satellite rainfall remote sensing for flood prediction. J. Geophys. Res., 109, D07102, doi:10.1029/2003JD003986.

Hou, A. Y., and Coauthors, 2014: The Global Precipitation Measurement Mission. Bull. Amer. Meteor. Soc., 95, 701-722, doi:10.1175/BAMS-D-13-00164.1.

Hsu, K.-L., X. Gao, S. Sorooshian, and V. Gupta, 1997: Precipitation estimation from remotely sensed information using artificial neural networks. J. Appl. Meteor., 36, 1176-1190, doi:10.1175/1520-0450(1997)036<1176:PEFRSI >2.0.CO;2.

Huffman, G. J., 1997: Estimates of root-mean-square random error contained in finite sets of estimated precipitation. J. Appl. Meteor., 36, 1191-1201, doi:10.1175/1520-0450(1997)036<1191: EORMSR $>2.0 . \mathrm{CO} ; 2$.

, R. F. Adler, D. T. Bolvin, G. Gu, E. J. Nelkin, K. P. Bowman, E. F. Stocker, and D. B. Wolff, 2007: The TRMM Multisatellite Precipitation Analysis: Quasi-global, multi-year, combinedsensor precipitation estimates at fine scale. J. Hydrometeor., 8, 38-55, doi:10.1175/JHM560.1.

, D. Bolvin, D. Braithwaite, K. Hsu, R. Joyce, C. Kidd, S. Sorooshian, and P. Xie, 2014: Early examples from the Integrated Multi-Satellite Retrievals for GPM (IMERG). Geophysical Research Abstracts, Vol. 16, Abstract EGU2014-11232. [Available online at http://meetingorganizer.copernicus.org/ EGU2014/EGU2014-11232.pdf.]

Janowiak, J. E., R. J. Joyce, and Y. Yarosh, 2001: A real-time global half-hourly pixel-resolution IR dataset and its applications. Bull. Amer. Meteor. Soc., 82, 205-217, doi:10.1175/ 1520-0477(2001)082<0205:ARTGHH > 2.3.CO;2.

Joyce, R. J., and P. Xie, 2011: Kalman filter based CMORPH. J. Hydrometeor., 12, 1547-1563, doi:10.1175/JHM-D-11-022.1. , J. E. Janowiak, and G. Huffman, 2001: Latitudinally and seasonally dependent zenith-angle corrections for geostationary satellite IR brightness temperature. J. Appl. Meteor., 40, 689-703, doi:10.1175/1520-0450(2001)040<0689:LASDZA > 2.0.CO;2.

_ - _ - P. A. Arkin, and P. Xie, 2004: CMORPH: A method that produces global precipitation estimates from passive microwave and infrared data at high spatial and temporal resolution. J. Hydrometeor., 5, 487-503, doi:10.1175/ 1525-7541(2004)005<0487:CAMTPG > 2.0.CO;2.

Kirstetter, P.-E., N. Viltard, and M. Gosset, 2013: An error model for instantaneous satellite rainfall estimates: Evaluation of BRAIN-TMI over West Africa. Quart. J. Roy. Meteor. Soc., 139, 894-911, doi:10.1002/qj.1964.

Y. Hong, J. J. Gourley, Q. Cao, M. Schwaller, and W. Peterson, 2014: Research framework to bridge from the Global Precipitation Measurement mission core satellite to 
the constellation sensors using ground-radar-based National Mosaic QPE. Remote Sensing of the Terrestrial Water Cycle, Geophys. Monogr., Vol. 206, Amer. Geophys. Union, 61-80, doi:10.1002/9781118872086.ch4.

Krajewski, W. F., and J. A. Smith, 2002: Radar hydrology: Rainfall estimation. Adv. Water Resour., 25, 1387-1394, doi:10.1016/ S0309-1708(02)00062-3.

Kummerow, C., and Coauthors, 2001: The evolution of the Goddard profiling algorithm (GPROF) for rainfall estimation from passive microwave sensors. J. Appl. Meteor., 40, 1801-1820, doi:10.1175/ 1520-0450(2001)040<1801:TEOTGP $>2.0 . C O ; 2$.

— W. Werg, J. Thomas-Stahle, and H. Masunaga, 2006: Quantifying global uncertainties in a simple microwave rainfall algorithm. J. Atmos. Oceanic Technol., 23, 23-37, doi:10.1175/ JTECH1827.1.

, S. Ringerud, J. Crook, D. Randel, and W. Berg, 2011: An observationally generated a priori database for microwave rainfall retrievals. J. Atmos. Oceanic Technol., 28, 113-130, doi:10.1175/2010JTECHA1468.1.

_ D. Randel, P. E. Kirstetter, M. Kulie, and N.-Y. Wang, 2014: Precipitation from the GPM Microwave Imager and constellation radiometers. Geophysical Research Abstracts, Vol. 16, Abstract EGU2014-1574. [Available online at http://meetingorganizer. copernicus.org/EGU2014/EGU2014-1574.pdf.]

Liao, L., R. Meneghini, and T. Iguchi, 2001: Comparisons of rain rate and reflectivity factor derived from the TRMM Precipitation Radar and the WSR-88D over the Melbourne, Florida, site. J. Atmos. Oceanic Technol., 18, 1959-1974, doi:10.1175/ 1520-0426(2001)018<1959:CORRAR > 2.0.CO;2.

Lin, X., and A. Y. Hou, 2008: Evaluation of coincident passive microwave rainfall estimates using TRMM PR and ground measurements as references. J. Appl. Meteor. And Climatol., 47, 3170-3187, doi:10.1175/2008JAMC1893.1.

Liu, C., E. J. Zipser, D. J. Cecil, S. W. Nesbitt, and S. Sherwood, 2008: A cloud and precipitation feature database from nine years of TRMM observations. J. Appl. Meteor. Climatol., 47, 2712-2728, doi:10.1175/2008JAMC1890.1.

Liu, G., and J. A. Curry, 1992: Retrievals of precipitation from satellite microwave measurements using both emission and scattering. J. Geophys. Res., 97, 9959-9974, doi:10.1029/ 92JD00289.

Munchak, S. J., and G. S. Skofronick-Jackson, 2013: Evaluation of precipitation detection over various surfaces from passive microwave imagers and sounders. Atmos. Res., 131, 81-94, doi:10.1016/j.atmosres.2012.10.011.

Petty, G. W., 1994: Physical retrievals of over-ocean rain rate from multichannel microwave imagery. Part I: Theoretical characteristics of normalized polarization and scattering indices. Meteor. Atmos. Phys., 54, 79-99, doi:10.1007/ BF01030053.

Ren, Z.-H., and Coauthors, 2010: Quality control procedures for hourly precipitation data from automatic weather stations in China (in Chinese with English abstract). Meteor. Monogr., 36, 123-132.

Saha, A., and Coauthors, 2010: The NCEP Climate Forecast System Reanalysis. Bull. Amer. Meteor. Soc., 91, 1015-1057, doi:10.1175/2010BAMS3001.1.

Sapiano, M. R. P., and P. A. Arkin, 2009: An intercomparison and validation of high-resolution satellite precipitation estimates with 3-hourly gauge data. J. Hydrometeor., 10, 149-166, doi:10.1175/2008JHM1052.1.

Shepard, D., 1968: A two dimensional interpolation function for irregularly spaced data. Proc. 23rd National Conf. of the
Association for Computing Machinery, Princeton, NJ, ACM, 517-524.

Simpson, J., R. F. Adler, and G. R. North, 1988: A proposed Tropical Rainfall Measuring Mission (TRMM) satellite. Bull. Amer. Meteor. Soc., 69, 278-294, doi:10.1175/1520-0477(1988)069<0278: APTRMM $>2.0 . C O ; 2$.

Tang, L., Y. Tian, and X. Lin, 2014: Validation of precipitation retrievals from satellite-based passive microwave sensors. J. Geophys. Res. Atmos., 119, 4546-4567, doi:10.1002/ 2013JD020933.

Tian, Y., C. D. Peters-Lidard, B. Choudhury, and M. Garcia, 2007: Multitemporal analysis of TRMM-based satellite precipitation products for land data assimilation applications. J. Hydrometeor., 8, 1165-1183, doi:10.1175/2007JHM859.1.

Turk, F. J., E. E. Ebert, B.-J. Sohn, H.-J. Oh, V. Levizzani, E. A. Smith, and R. Ferraro, 2004: Validation of an operational global precipitation analysis at short time scales. Preprints, 12 th Conf. on Satellite Meteorology and Oceanography, Seattle, WA, Amer. Meteor. Soc., JP1.2. [Available online at https://ams. confex.com/ams/annual2003/techprogram/paper_56865.htm.]

Ushio, T., and Coauthors, 2009: A Kalman filter approach to the Global Satellite Mapping of Precipitation (GSMaP) from combined passive microwave and infrared radiometric data. J. Meteor. Soc. Japan, 87A, 137-151, doi:10.2151/jmsj.87A.137.

Vicente, G. A., J. C. Davenport, and R. A. Scofield, 2002: The role of orographic and parallax corrections on real time high resolution satellite rainfall rate distribution. Int. J. Remote Sens., 23, 221-230, doi:10.1080/01431160010006935.

Wang, C., Z. J. Luo, and X. Huang, 2011: Parallax correction in collocating CloudSat and Moderate Resolution Imaging Spectroadiometer (MODIS) observations: Method and application to convection study. J. Geophys. Res., 116, D17201, doi:10.1029/2011JD016097.

Wang, N.-Y., C. Liu, R. Ferraro, D. Wolff, E. Zipser, and C. Kummerow, 2009: TRMM 2A12 land precipitation productStatus and future plans. J. Meteor. Soc. Japan, 87A, 237-253, doi:10.2151/jmsj.87A.237.

Wilheit, T. T., A. T. C. Chang, and L. S. Chiu, 1991: Retrievals of monthly rainfall indices from microwave radiometric measurement using probability distribution functions. J. Atmos. Oceanic Technol., 8, 118-136, doi:10.1175/1520-0426(1991)008<0118: ROMRIF $>2.0 . \mathrm{CO} ; 2$.

Wolff, D. B., and B. L. Fisher, 2008: Comparisons of instantaneous TRMM ground validation and satellite rain-rate estimates at different spatial scales. J. Appl. Meteor. Climatol., 47, 22152237, doi:10.1175/2008JAMC1875.1.

— microwave-based satellite rain-rate retrievals using TRMM ground validation data. J. Appl. Meteor. Climatol., 48, 10691099, doi:10.1175/2008JAMC2127.1.

, D. A. Marks, E. Amitai, D. S. Silberstein, B. L. Fisher, A. Tokay, J. Wang, and J. L. Pippitt, 2005: Ground validation for the Tropical Rainfall Measuring Mission (TRMM). J. Atmos. Oceanic Technol., 22, 365-380, doi:10.1175/ JTECH1700.1.

Xie, P., and A.-Y. Xiong, 2011: A conceptual model for constructing high-resolution gauge-satellite merged precipitation analyses. J. Geophys. Res., 116, D21106, doi:10.1029/ 2011JD016118.

—_, and R. Joyce, 2014: Integrating information from satellite observations and numerical models for improved global precipitation analyses: Exploring for an optimal strategy. Remote Sensing of the Terrestrial Water Cycle, Geophys. 
Monogr., Vol. 206, Amer. Geophys. Union, 43-60, doi:10.1002/ 9781118872086.ch3.

M. Chen, A. Yatagai, T. Hayasaka, Y. Fukushima, and S. Yang, 2007: A gauge-based analysis of daily precipitation over East Asia. J. Hydrometeor., 8, 607-626, doi:10.1175/ JHM583.1.

Yang, H., X.-Q. Li, R. You, and S.-L. Wu, 2013: Environmental data records from FengYun-\#B microwave radiation imager (in Chinese with English abstract). Adv. Meteor. Sci. Technol., 3, 136-143.

Yang, S., W. S. Olson, J. J. Wang, T. L. Bell, E. A. Smith, and C. D. Kummerow, 2006: Precipitation and latent heating distributions from satellite passive microwave radiometry. Part II: Evaluation of estimates using independent data. J. Appl. Meteor. Climatol., 45, 721-739, doi:10.1175/ JAM2370.1.

Zhang, J., and Coauthors, 2011a: National Mosaic and Multisensor QPE (NMQ) system: Description, results, and future plans. Bull. Amer. Meteor. Soc., 92, 1321-1338, doi:10.1175/ 2011BAMS-D-11-00047.1.

_, Y. Qi, K. Howard, C. Lanston, and B. Kaney, 2011b: Radar Quality Index (RQI) - A combined measure for beam blockage and VPR effects in a national network. IAHS Publ., 351, 388-393. 